\title{
The homeoprotein ENGRAILED-1 promotes motoneuron survival and sustains motor functions
}

\section{Abbreviated title: Motoneuron protection by Engrailed-1}

Stephanie E. Vargas Abonce ${ }^{1}$, Mélanie Lebœuf ${ }^{1,2}$, Kenneth L. Moya $^{1}$ and Alain Prochiantz ${ }^{1}$

${ }^{1}$ Centre for Interdisciplinary Research in Biology (CIRB), Collège de France, CNRS UMR 7241 / INSERM U1050, PSL Research University, Labex Memolife Paris Science et Lettres, 11 place Marcelin Berthelot 75005 Paris

${ }^{2}$ BrainEver, 74 rue du Faubourg Saint-Antoine, 75012 Paris.

Author contributions: SEVA and ML contributed equally to this paper. AP and KLM designed research; SEVA and ML performed research; SEVA, ML and KLM analyzed data, SEVA, ML, AP and KLM wrote the paper.

Correspondence should be addressed to ken.moya@college-de-france.fr.

Acknowledgements: We thank the College de France Imaging facilities and animal service for assistance in some of the analyses. We are also grateful to Drs. Anne Bousseau and Yoko Arai for very helpful discussion during the study and Angélique Bibimbou for excellent technical assistance.

Conflict of Interest Statement: A.P and K.L.M. are listed on several patents for the use of HPs for the treatment of neurodegenerative disease. They are co-founders and hold shares in a company developing HPs for therapeutic use.

Funding sources: MemoLife Labex PhD fellowship to SEVA, Association Nationale de la Recherche et de la Technologie (Cifre/ANRT n 2017/0488) to ML, BrainEver, HomeoSign ERC -2013-AdG n³39379 


\begin{abstract}
In addition to their cell autonomous activities, a number of homeoprotein transcription factors transfer between cells and regulate gene transcription, protein translation and chromatin organization in a non-cell autonomous way. ENGRAILED-1 homeoprotein is endowed with the latter properties and is expressed in spinal cord V1 inhibitory interneurons that synapse on large spinal cord $\alpha$-motoneurons. Based on the neuroprotective effects of several homeoproteins in the adult central nervous system, we have analyzed the motor phenotype of mice lacking one functional Engrailed-1 allele. Engrailed-1 heterozygote mice with Engrailed-1 expression reduced by half in the spinal cord start to show muscle weakness, abnormal spinal reflex and partial neuromuscular junction denervation between 2 and 3 months of age. Alpha-motoneuron degeneration is first observed at 4.5 months and progresses with time, reaching 50 per cent in 15.5-month-old mice. A single intrathecal injection of exogenous recombinant human ENGRAILED-1 at 3 months in the lumbar enlargement allows for an addressing of the protein to lumbar $\alpha$-motoneurons and, to a lesser degree, to cervical ones. This results in full restoration of strength and extensor reflex for at least 2 months, in parallel with a preservation of the number of lumbar $\alpha$-motoneurons, and blocks endplate denervation. The similarities of the Engrailed-1 heterozygote phenotype to motor neuron disease symptoms and the long-lasting effects of a single ENGRAILED-1 injection suggests that this approach may be of interest in the search for therapies alleviating the consequences of $\alpha$-motoneuron degeneration.
\end{abstract}




\section{INTRODUCTION}

Homeoprotein transcription factors are encoded by a class of genes discovered on the basis of their developmental functions ${ }^{1}$. More recently, it was shown that several of them are also expressed in the adult, suggesting that they participate in physiological homeostasis ${ }^{2,3}$. Similarly to what has been observed during development, adult homeoprotein (HP) functions involve both cell autonomous and non-cell autonomous properties ${ }^{4,5}$. Non-cell autonomous properties arise from the ability of several HPs to transfer between cells due to two highly conserved sequences present in their DNA-binding domain or homeodomain ${ }^{6-9}$. Examples of non-cell autonomous activities in the central nervous system, include the regulation of cerebral cortex plasticity and retinal ganglion cell (RGC) survival by OTX2 ${ }^{10-12}$, the control of oligodendrocyte precursor cell and Cajal-Retzius cell migration by PAX6 ${ }^{13,14}$ and the axon guidance activities of ENGRAILED-2 and VAX-1 ${ }^{15-17}$.

An important ENGRAILED-1 (EN1) function is to ensure the survival of mesencephalic dopaminergic (mDA) neurons of the Substantia Nigra pars compacta (SNpc). In En1 heterozygote (Enl-Het) mice, mDA neurons die progressively starting at post-natal week 6 and only approximately $60 \%$ of them remain in one-year-old mice ${ }^{18}$. Infusion or injection of $\mathrm{EN} 1$ or EN2 proteins at the level of the $\mathrm{SNpc}$ and their internalization by $\mathrm{mDA}$ neurons rescues these neurons from degeneration in several Parkinson Disease mouse models ${ }^{18-20}$ and in a primate model ${ }^{21}$. Following a single EN1 injection in mice, mDA rescue lasts for several weeks, a long-lasting effect reflecting that EN1, in addition to directly regulating transcription and translation ${ }^{5,22,23}$, also works as an epigenetic chromatin remodeler ${ }^{20,24}$.

In the ventral spinal cord, En-1, but not En2, is expressed in V1 inhibitory interneurons ${ }^{25-29}$ which form inhibitory GABAergic and glycinergic synapses on large $\alpha$-motoneurons ( $\alpha \mathrm{MNs})$ 30,31 and regulate alternating flexor-extensor activity $28 \mathrm{32}^{32}$. They contribute to the excitatory/inhibitory balance with excitatory V0 interneurons and the maintenance of this balance may be important for $\alpha \mathrm{MN}$ survival ${ }^{30}$.

In light of our studies demonstrating that EN1, EN2 and OTX2 have pro-survival activities 5 , we investigated whether EN1 expressed by V1 interneurons may be important for $\alpha \mathrm{MN}$ physiology and survival with which they are in synaptic contact. We demonstrate that Enl 
bioRxiv preprint first posted online Aug. 13, 2019; doi: http://dx.doi.org/10.1101/734020. The copyright holder for this preprint

(which was not peer-reviewed) is the author/funder, who has granted bioRxiv a license to display the preprint in perpetuity.

All rights reserved. No reuse allowed without permission.

expression is maintained in adulthood and that Enl-Het mice have early muscle weakness and abnormal spinal reflex associated with partial denervation of the neuromuscular junction (NMJ) and a later loss of large $\alpha \mathrm{MNs}$. These degenerative changes are progressive, increasing between 2 and 15.5 months of age. A single intrathecal injection of human recombinant EN1 (hEN1) at 3 months restores muscle strength, normalizes spinal reflex and NMJ innervation and promotes survival of $\alpha \mathrm{MNs}$. This restorative and protective activity lasts for at least 2 months. 


\section{MATERIALS AND METHODS}

\section{Animal Management}

All animals were treated in accordance with the guideline for the care and use of laboratory animals (US National Institutes of Health), the European Directive number 86/609 (EEC Council for Animal Protection in Experimental Research and Other Scientific Utilization) and French authorizations $n^{\circ} 00703.01$ "Therapeutic homeoproteins in Parkinson Disease" and $\mathrm{n}^{\circ}$ APAFIS \#6034-2016071110167703 v2, “Spinal cord motoneurons neuroprotection” delivered by the Minister of higher education, research and innovation.

Adult mice were housed two to five per cage and maintained with ad libitum food and water, under a 12h light/dark cycle. Transgenic mouse strain Enl-Het was bred by the Rodent Breeding Services provided by the Animal Care Services at College de France. Colony maintenance and genotyping were performed as previously described ${ }^{33}$. Both, females and males were included in all the studies.

\section{Assessment of disease progression and humane end-point}

Mice were considered for euthanasia if they displayed 15\% loss of bodyweight or showed signs of paralysis, whichever was reached first. None of the mice were euthanized due to these reasons.

\section{Behavioral analyses}

The tests used to evaluate muscle strength and spinal reflexes are forepaw grip strength test, inverted grid test and hindlimb extension reflex. Mice were habituated to the behavioral room and experimenter 24 hours before the day of testing and again 1 hour before each behavioral test. All tests were performed the same day and behavioral assessment was carried by evaluators blind to genotype and treatment. Mice were weighed before each session.

Forepaw Grip Strength. The Transducer (IITC Life Science Grip Strength Meter, ALMEMO 2450 AHLBORN, World Precision Instruments) was calibrated and the scale of the values set to grams. During the test, each mouse was lifted by the tail to position the front paws at the height as the bar (about $15 \mathrm{~cm}$ ) and moved towards the bar. Symmetric firm grip with both paws was verified and the mouse was pulled backward at a constant speed until the grasp was broken and the maximal value was recorded. The test was repeated 5 times per animal with a 
minimal resting time of 5 minutes between tests and the mean of all values was normalized to the weight of each animal. At least 4 mice per group per experiment were used.

Inverted Grid Test. The mouse was placed on a wire grid $(15 \times 10 \mathrm{~cm})$ and let to freely explore it. After 3-5 minutes, the grid was raised $30 \mathrm{~cm}$ above a soft surface and gently turned upside down. Latency to falling was recorded three times per mouse with a minimum resting time of 5 minutes between trials. The longest latency was used for further analysis.

Hindlimb Extensor Reflex. Mice were gently suspended by the tail at a constant height (30 $\mathrm{cm}$ ) and scored for hindlimb extension reflex. The scores were assigned from 0 to 3 as follows: 3 normal symmetric extension in both hind limbs without visible tremors; 2.5 normal extension in both hind limbs with tremor in one or both paws; 2.0 unequal extension of the hind limbs without visible tremors; 1.5 unequal extension in the hind limbs with tremors in one or both paws, 1.0 extension reflex in only one hindlimb, 0.5 minimum extension of both hindlimbs, 0 absence of any hindlimb extension.

\section{Tissue preparation}

Spinal cord. Adult mice were euthanized by an overdose of Dolethal (Pentobarbital, Vétoquinol) (1 $\mu \mathrm{l} / \mathrm{g}$ body weight). The spinal cord was dissected after laminectomy and placed in PBS $(20 \mathrm{mM} \mathrm{PO}, 155 \mathrm{mM} \mathrm{NaCl})$ to remove the meninges and surrounding connective tissue. Cervical and Lumbar enlargements were separated and placed in Paraformaldehyde 4\% (PFA, Thermo Scientific) for 1 hour at room temperature with mild mixing. The tissue was then washed in PBS, three times for 30 minutes at room temperature and placed in PBS, $20 \%$ sucrose overnight at $4^{\circ} \mathrm{C}$. After cryoprotection, the spinal cords were embedded in Tissue Freezing Medium (TFM, Microm Microtech), frozen on dry ice and 30 $\mathrm{MM}$ sections prepared on an HM 560 Microm cryostat (Thermo Scientific).

Muscle. The extraocular (EOM), tongue and lumbrical muscles from the plantar surface of the paw were dissected into cold PBS and fixed at room temperature in 4\% PFA for 10 minutes for extraocular and lumbrical muscles or 1 hour for the tongue. The muscles were then washed in PBS and cryoprotected. Extraocular and lumbrical muscles whole-mounts were stained to allow for visualization of the entire innervation pattern and detailed analysis of the neuromuscular junctions ${ }^{34}$. Tongue muscles were embedded and sectioned at $30 \mu \mathrm{m}$. 
Cresyl violet staining. Slides with $30 \mu \mathrm{M}$ spinal cord sections were washed in PBS (1X) 3 times, cleared in O-Xylene (CARLO-HERBA) for 5 minutes, then hydrated in graded alcohols with increasing water and placed in Cresyl Violet acetate (MERCK). Sections where then dehydrated in increasing alcohols and mounted.

\section{RT-qPCR}

Spinal cords were removed as above and cervical and lumbar enlargements were separated and rapidly frozen on dry ice. Total RNA was extracted (RNeasy Mini kit, Qiagen) and reverse transcribed using the QuantiTect Reverse Transcription kit (Qiagen). RT-qPCR were done using SYBR-Green (Roche Applied Science) and Light Cycler 480 (Roche Applied Science). Data were analyzed using the «2-ddCt $»$ method and values were normalized to Glyceraldehyde 3-phosphate dehydrogenase (Gapdh). The following primers were used: Engrailed-1 sense: CCTGGGTCTACTGCACACG, antisense: CGCTTGTTTTGGAACCAGAT; Gapdh sense: TGACGTGCCGCCTGGAGAAAC, antisense: CCGGCATCGAAGGTGGAAGAG

Spinal cord and muscle immunofluorescent labeling. Slides with $30 \mu \mathrm{m}$ spinal cord or muscle sections were washed in PBS and permeabilized with 2\% Triton. After 30 minutes at RT in $100 \mu \mathrm{M}$ glycine buffer, sections were blocked in 10\% Normal Goat Serum (NGS, Invitrogen) or Fetal Bovine Serum (FBS, Gibco) in the presence of 1\% Triton and incubated with primary antibodies (Sheep anti-Choline Acetyltransferase -ABCAM, 1:1000- or goat anti-Choline Acetyltransferase -Millipore, 1:500-, rabbit anti-Engrailed1 -1:300-, mouse anti-neurofilament $165 \mathrm{kDa}$-DSHB, 1:50- and mouse anti-synaptic vesicle glycoprotein 2A -DSHB, 1:100-) overnight at $4{ }^{\circ} \mathrm{C}$, washed and further incubated with corresponding secondary antibodies for 2 hours at room temperature. For muscle staining, $\alpha$-bungarotoxin (Alexa fluor 488 conjugate) was used at the same time as the secondary antibodies. Slides were washed and mounted with DAPI Fluoromount-G® (Southern Biotech). Controls without primary antibodies were systematically included.

\section{Protein production}

Human EN1 (hEN1) was produced as described ${ }^{11}$ and endotoxins were removed by Triton X144 phase separation ${ }^{35}$. In brief, pre-condensed 1\% Triton X-144 (Sigma) was added to the protein preparation. The solution was incubated 30 minutes at $4{ }^{\circ} \mathrm{C}$ with constant stirring, 
transferred to $37^{\circ} \mathrm{C}$ for 10 minutes and centrifuged at $4000 \mathrm{rpm}$ for 10 minutes at $25^{\circ} \mathrm{C}$. The endotoxin-free protein was aliquoted and kept at $-20^{\circ} \mathrm{C}$.

\section{Intrathecal injections}

Mice were anesthetized with ketamine (Imalgene 1000) and xylazine (Rompur 2\%) in $\mathrm{NaCl}$ $50 \mathrm{mM}$ and placed on the injection platform. The tail of the animal was taken between two fingers of one hand and its back was gently flattened with the other hand. The L3 vertebral spine was identified by palpation and a $23 \mathrm{G} \times 1 "$ needle $(0.6 \times 25 \mathrm{~mm}$ Terumo tip) was placed at the L1 and T13 groove and inserted through the skin at an angle of $20^{\circ}$ (Hylden and Wilkox, 1980). The needle was slowly advanced forward to the intervertebral space until it reached the injection point, provoking a strong tail-flick reflex. Five $\mu 1$ were injected at a rate of $1 \mu 1 / \mathrm{min}$ with or without $1 \mu \mathrm{g}$ recombinant protein. The needle was left in place for two minutes after injection and then slowly removed. Animals were placed in a warmed recovery chamber until awakening. Extensor reflex and gait analysis were examined 2 and 24 hours after injection to ascertain the absence of spinal cord damage.

\section{Image analyses}

Cresyl violet stained spinal cord section images were acquired with a Nikon-i90 microscope under bright field conditions at $10 \mathrm{x}$ with a Z-stack step of $0.5 \mu \mathrm{m}$. Immunofluorescence stained spinal cord sections images were acquired with a Leica SP5 inverted confocal microscope at 20x (Leica DMI6000) and acquisitions of 3D z-stack $(0.5 \mu \mathrm{M})$ were made using the UV (405 nm, 50mW), Argon (488 nm, 200mW) and DPSS (561 nm, 15mW) lasers. For MN quantification, at least five spinal cord sections separated by $\geq 900 \mu \mathrm{m}$ were analyzed for each animal. ChAT+ cells and Cresyl stained cells with a cell soma area greater than $100 \mu \mathrm{m}^{2}$ were manually outlined using ImageJ software (NIH, Bethesda, MD) and their area determined. Analyses were carried out on Z-stacks through the entire $30 \mu \mathrm{m}$ thickness of the section. Cells were classified as small (100-199 $\mu \mathrm{m}^{2}$ cross sectional area), intermediate (between 200-299 $\mu^{2}$ ) and large (greater than $300 \mu \mathrm{m}^{2}$ ).

Lumbrical, EOM and tongue muscles were imaged with a Leica SP5 inverted confocal microscope (Leica DMI6000) with a motorized XY stage. 3D z-stack $(0.5 \mu \mathrm{M})$ acquisitions were made as indicated above (UV, Argon and DPSS) and images analyzed using ImageJ software. Analyses were performed blind to the genotype and treatment. Endplates where categorized as fully innervated (neurofilament overlying more than $80 \%$ of the endplate), 
partially innervated (neurofilament overlying up to $80 \%$ of the endplate) or denervated (no neurofilament overlying the endplate) ${ }^{36}$. Endplate morphology was evaluated by counting the number of endplates with perforations (areas lacking $\alpha$-bungarotoxin staining). For postsynaptic analysis, each endplate was manually outlined using ImageJ software and area calculated. All analyses were done on the entire Z-stacks through the NMJ.

\section{Statistical analyses}

Results are based on seven independent experiments. Muscle weakness and abnormal reflex score in 3-month-old En1-Het mice was observed in 6-7 of the 7 experiments, NMJ denervation in 5 of 5 experiments and $\alpha \mathrm{MN}$ loss in 4 of 4 . The restoration of muscle strength and normalization of the spinal reflex after hEN1 injection was observed in 5 of 5 experiments and a significant increase in $\alpha \mathrm{MN}$ survival in 4 of 4 experiments.

Data are expressed as mean \pm SD unless otherwise indicated. Statistical significance was determined as indicated. For RT-qPCR, WT and En1-Het mice were compared by Unpaired T-test with equal SD. For behavioral and NMJ analyses and MN counting in the time-course study, groups were compared by Unpaired T-test with equal SD comparing WT with En1-Het for each time point. For the intrathecal injections, behavioral and NMJ analyses and $\mathrm{MN}$ counting, experimental data were compared by one-way ANOVA followed by a post hoc Dunnett's test for comparisons to WT. For behavioral analysis in the time-course protection of injected hEN1, groups were compared by Unpaired T-test with equal variances comparing WT with Enl-Het injected at each time point. For behavioral analysis in the time-course protection experiment following the injection of hEN1 in 9-month-old mice and of the hEN1 mutant hEN1Q50A, groups were compared by One-Way-ANOVA with Tukey's multiple comparisons test comparing the groups for each time point. 


\section{RESULTS}

\section{En1-Het mice show early and progressive motor deficits}

Previous studies reported Enl expression in V1 interneurons in the early postnatal mouse spinal cord ${ }^{29}$. We verified that this expression is maintained at the same levels throughout life and is decreased by twofold in the Enl-Het mouse both at 4.5 and 16 months, thus during the time frame of all experiments (Fig. 1a, b). This indicates that V1 interneurons survival is preserved in the Enl-Het mice, in contrast with the situation for mDA neurons of the SNpc ${ }^{18}$. En1-Het mice display the same average weight gain as their WT littermates at all ages studied (Fig. 1c). For the three tests used to assess muscle strength, WT and Enl-Het animals evolved differently, the latter showing signs of loss of strength compared to their WT littermates (Fig. 1d-f). At one and two months of age forepaw grip strength was similar in Enl-Het and WT mice, but a significant reduction was first measurable at 3 months that persisted through 15.5 months of age (Fig. 1d). The inverted grid test assesses the ability of the four limbs to resist gravity. Two-month-old Enl-Het mice resisted significantly less than WT mice and holding time further diminished between two months and 15.5 months, revealing a progressive loss of strength (Fig. 1e). Finally, the hind limb extensor reflex was taken to monitor purely spinal function. WT mice had an extensor score of about three at all ages but the score of the EnIHet animals started to deteriorate overtime between 2 and 15.5 months (Fig. 1f). Taken together, these results show that Enl-Het mice have a progressive loss of muscle strength and a deteriorating spinal reflex compared to WT siblings.

\section{Presynaptic pathology in the neuromuscular junction of the lumbrical muscles in En1-}

\section{Het mice}

Motor deficits are often accompanied by early synaptic changes at the NMJ, a specialized synapse between $\alpha \mathrm{MN}$ axon terminals and skeletal muscle fibers. Since NMJs are highly vulnerable from very early stages of motor disorders, we analyzed the NMJ morphology and synaptic characteristics of three muscle groups with different degrees of vulnerability in neuromuscular diseases ${ }^{36}$. Data corresponding to lumbrical endplates are described in Figure 2 and those corresponding to extraocular and tongue muscles in Supplemental Figure 1.

Alpha-bungarotoxin and antibodies against neurofilament and synaptic vesicle protein $2 \mathrm{~A}$ were used in combination to visualize acetylcholine receptor (AChR) clusters of the motor 
endplate and motor axon terminals, respectively (Fig. 2a). The typical endplate morphology well centered on the lumbrical muscle fibers was observed in all mice examined ${ }^{34}$. No changes were found in the average number of AChR clusters between WT and Enl-Het mice (Fig. 2b). The area of the motor endplate did not differ between WT and Enl-Het mice throughout 9 months of age, and is significantly reduced in Enl-Het mice at 15.5 months of age (Fig. 2c). Endplate perforations (post-junctional folds) are a region of the endplate devoid of AChR. Their number reflects the state of maturation of the NMJ and normal healthy muscles show a complex morphology with multiple perforations ${ }^{37}$. The percentage of endplates with perforations shows no difference between WT and Enl-Het mice throughout 9 months of age (Fig. 2d) but is significantly reduced in the Enl-Het mice at 15.5 months of age. Finally, the lumbrical NMJ innervation was evaluated. Motor endplates where categorized as fully innervated if neurofilament immunoreactivity overlaid more than $80 \%$ of the endplate. Figure 2e shows the significantly reduced NMJ innervation in EnI-Het mice, starting at 3 months and worsening with age.

In contrast with lumbrical endplates, no differences between the two genotypes were observed in any of the NMJ morphological characteristics for extraocular and tongue muscles, at any age (Supp. Fig 1).

\section{Loss of large $\alpha \mathrm{MN}$ in the En1-Het mouse spinal cord}

The progressive muscle weakness of the Enl-Het is paralleled with a partial denervation of the muscle fibers possibly reflecting $\alpha \mathrm{MN}$ loss. We thus analyzed the number of neurons present in the cervical and lumbar enlargements of the spinal cord in the En1-Het mice and their WT littermates. At 15.5 months, the total number of Cresyl-stained neurons in the ventral spinal cord was similar for the cervical (Supp. Fig 2) and lumbar enlargements at 15.5 months (Fig. 3a,b). In contrast, a decrease in the number of large densely stained cells was clearly apparent in the Enl-Het mouse spinal cord. To understand this, the neurons were classified according to their surface: small neurons of $100-199 \mu \mathrm{m}^{2}$, intermediate size neurons of $200-299 \mu \mathrm{m}^{2}$, and large neurons $300 \mu \mathrm{m}^{2}$ or more. The number of small and intermediate size neurons remained constant at all ages, with no difference between Enl-Het and WT mice (Fig. 3c, d) while the number of large neurons decreased progressively between months $4.5(\approx$ $20 \%$ loss) and 15.5 ( $\approx 50 \%$ loss) in En1-Het animals (Fig. 3e). 
Choline Acetyltransferase (ChAT) is selectively expressed in $\gamma$ and $\alpha \mathrm{MNs}$ that can be distinguished on the basis of size ${ }^{38}$. In order to better identify the neurons that are lost in the ventral spinal cord of Enl-Het animals we used ChAT immunoreactivity in 9-month-old mice. Compared to WT, Figure 4a clearly shows a loss of large ChAT+ cells in the En1-Het spinal cord and Figure 4b-c which compares Cresyl violet and ChAT staining for medium size and large neurons, confirms that the cells that disappear in the Enl-Het mutant are $\alpha \mathrm{MNs}$. It is of note that the loss of large $\alpha \mathrm{MNs}$ in the Enl-Het mouse spinal cord is not accompanied by a corresponding increase in the intermediate size class of MNs, precluding $\alpha \mathrm{MN}$ shrinkage.

Taken together, these results show that, compared to WT, Enl-Het mice present a loss of large $\alpha \mathrm{MNs}$ in the ventral spinal cord that is first apparent at 4.5 months and progresses with time, reaching about $50 \%$ at 15.5 months of age.

\section{Recombinant hEN1 reverses the En1-Het motor phenotype, restores NMJ morphology and reduces $\alpha \mathrm{MN}$ loss}

Previously, we showed that exogenous HP transcription factors, including EN1, EN2 and OTX2, rescue mDA neurons and RGCs from an in vivo stress ${ }^{11,19,20}$ and that this survival effect holds for several weeks following a single HP injection ${ }^{11}{ }^{20}$. This led us to test whether a single intrathecal hEN1 injection into the spinal cord of Enl-Het mice could have total or partial rescuing activities on any of the analyzed phenotypes. In the En1-Het mice muscle weakness and abnormal extensor reflex appear between 2 and 3 months (Fig. 1) while $\alpha \mathrm{MN}$ loss is only visible at 4.5 months (Fig. 3e), suggesting that three months of age is a valuable "therapeutic" window. One $\mu \mathrm{g}$ of hEN1 was injected and $24 \mathrm{~h}$ later strong EN1 immunofluorescence was detected in the perivascular space and in neurons of lumbar spinal and cervical cord (Fig. 5a, b). ChAT immunofluorescence showed that many of the cells that internalized hEN1 are large-sized $\alpha \mathrm{MNs}$ and that the number of hEN1-stained cells was much lower in the cervical region probably due to its distance from the lumbar injection site (Fig. $5 b)$.

Three-month-old En1-Het and WT mice were evaluated for muscle weakness and hindlimb extensor reflex and, 2 days later, Enl-Het mice were separated into two groups. A first group received $5 \mu \mathrm{l}$ of vehicle and the other $1 \mu \mathrm{g}$ of hEN1 in $5 \mu \mathrm{l}$ of vehicle without incidence on weight (Fig. 5c). As already shown, before intrathecal injections, En1-Het mice (compared to WT siblings) had reduced forepaw grip strength, reduced time holding onto the inverted grid 
and had a slightly lower hind limb reflex score (Fig. 5d-f). One month and a half later, En1Het mice treated with vehicle continued to do worse than WT mice in the three tests whereas the performance of hEN1 injected mice were undistinguishable from those of WT controls (Fig. 5d-f). Synapse morphology and $\alpha \mathrm{MN}$ death were analyzed in the 4.5-old-mice injected at 3 months with vehicle or hEN1. The percentage of fully occupied endplates, reduced in En1-Het mice (Fig. 2), returns to normal in hEN1 treated animals (Fig. 6a). At 3 months of age, Enl-Het mice have a normal number of $\alpha \mathrm{MNs}$ characterized by size and ChAT staining, but some loss has already occurred 1.5 months later (Fig. 3e). Figure 6 (b, c) illustrates that the number of Cresyl-stained large cells and ChAT-stained large cells at the lumbar enlargement is identical at 4.5 months between WT mice and Enl-Het siblings injected with hEN1 at month 3.

As a control, a mutant of hEN1 (hEN1Q50A) in which glutamine in position 50 of the homeodomain was mutated into alanine, thus allowing internalization but preventing high affinity binding to DNA ${ }^{39}$ was also injected but showed no rescuing activity (Supp. Fig 3).

Taken together, these experiments demonstrate that a single hEN1 injection at month 3 and at the lumbar level restores muscle strength, normalizes the spinal reflex and restores a normal NMJ morphology. In addition, the treatment blocks lumbar, but not cervical $\alpha \mathrm{MN}$ degeneration, for a period of at least 1.5 months (Supp. Fig 4). That En1-Het mouse muscle strength is restored in the forepaw grip strength and inverted grid tests suggests that the surviving $\alpha \mathrm{MNs}$ in the cervical enlargement have benefited from hEN1 injection.

\section{A single hEN1 injection at 3 months of has long-lasting effects on En1-Het mice and no effect at 9 months}

To investigate if the rescue effect of a single hEN1 injection in three-month-old En1-Het mice could last more than 1.5 months, $1 \mu \mathrm{g}$ of hEN1 was injected in three-month-old EnI-Het mice that were assessed weekly during the first month following injection and then monthly up to six months. Before injection, three-month-old En1-Het mice showed significant muscle weakness and an abnormal reflex compared to WT mice (Fig. 7a-c). One week after injection the forepaw grip strength and the extensor reflex in the En1-Het mice were normalized to WT values. This improvement was fully maintained for 3 months, after which performance declined progressively to reach pre-injection levels. The improvement in the inverted grid test 
was more modest but followed a similar time course. When compared to 9-month-old untreated En1-Het mice, mice injected with hEN1 at 3 months and kept for 6 months did not maintain wild type values but performed better in the 3 tests than untreated age-matched EnIHet mice. At the end of the study, muscles and spinal cord tissue were dissected and analyzed. Figure 8 shows that Enl-Het mice treated with hEN1 show higher NMJ innervation at 9 months than untreated age-matched En1-Het mice, although less than WT littermates (Fig. 8a). A similar partial rescue at 9 months was also observed for $\alpha \mathrm{MN}$ survival (Fig. 8b). These results suggest that a single injection of $\mathrm{hEN} 1$ slows the degenerative processes that normally occur in the Enl-Het mice.

To examine whether late administration of hEN1 would have positive effects on the En1-Het phenotype, $1 \mu \mathrm{g}$ of $\mathrm{hEN1}$ or vehicle was injected in 9-month-old En1-Het mice. Before injection, Enl-Het mice manifested significant reductions in forepaw grip strength, time of holding onto the inverted grid and extensor reflex score (Fig. 7d-f). Compared to WT siblings, vehicle and hEN1-injected Enl-Het mice continued to be significantly impaired in the three tests, although, one may notice a very small improvement of the hEN1-treated Enl-Het mice, two months post injection, for the forepaw grip strength and extensor reflex tests. At the end of the experiment the now 15.5-month-old mice were dissected to analyze NMJ occupancy and count the surviving $\alpha \mathrm{MNs}$. As shown in Figure $8 \mathrm{c}-\mathrm{d}$, injection after 9 months had no effect on either morphological criteria evaluated at the lumbar enlargement or for hindlimb muscles. 


\section{DISCUSSION}

This study establishes the importance of EN1 expression in $\alpha \mathrm{MN}$ survival and motor strength. It also shows that one intrathecal injection of hEN1 can rescue the En1-Het phenotype with a long-lasting activity when the injection is made before degeneration has reached a no-return point, as in 9-month-old En1-Het mice. In this study, we used the human recombinant protein, but the human and mouse proteins are $91.1 \%$ identical and were used with the same efficiency in mDA neuron survival experiments ${ }^{19-21,24}$.

A day after injection hEN1 is present around vascular structures probably in the perivascular space from which it penetrates into the parenchyma and reaches the cell interior. Indeed, it has been shown before that EN1 and EN2, similarly to many HPs ${ }^{5,9}$ translocate across the plasma membrane to reach the cell cytoplasm through a mechanism distinct of endocytosis ${ }^{8}$. The examination of the ventral horns suggests a preferential accumulation in neurons, not precluding the possibility that other cells types, in particular astrocytes, also capture the protein. Among the neurons, the large neurons with a morphology evoking $\alpha \mathrm{MN}$ are systematically more strongly labeled than the medium and small size ones. Although this requires a more detailed study, it might reveal that, physiologically, EN1 expressed by the V1 neurons is secreted and internalized by $\alpha$ MNs expressing EN1-binding sites.

The latter hypothesis is in line with what was demonstrated in the case of OTX2, a HP which is specifically recognized in the cerebral cortex by a class of interneurons expressing parvalbumin ${ }^{10}$. OTX2 internalization is due to its recognition by glycosaminoglycans (GAG) present at the surface of these interneurons thanks to the GAG binding domain (RKQRRERTTFTRAQL) overlapping with the first helix of the homeodomain 40 . Interestingly, similar GAG-binding domains are present upstream of the homeodomain in many HPs ${ }^{3,5}$, including EN1 and EN2 for which this putative GAG-binding sequence is KEDKRPRTAFTAEQL. The potential role of this domain in the specific targeting of EN1 and the presence of EN1 binding sites at the $\alpha \mathrm{MN}$ surface will be investigated in further studies.

A striking observation is that, in the En1-Het mouse, the extensor reflex score is reduced at 2 months and muscle strength between 2 and 3 months. This corresponds to the decrease in 
fully occupied endplates first observed at 3 months and this precedes the loss of $\alpha \mathrm{MNs}$ observed at 4.5 months. This slight temporal discrepancy probably reflects that the $\alpha \mathrm{MNs}$ are experiencing retrograde degeneration with the terminals, thus strength, affected before cell body loss. This replicates what occurs in Enl-expressing mDA neurons in the same En1-Het mouse line: their terminals show degeneration signs at 4 weeks, whereas the neurons only start dying at 6 weeks of age ${ }^{18,41}$. In this context, it is important to note that hEN1 injection at 3 months not only prevents $\alpha \mathrm{MN}$ death for weeks, but also restores normal endplate morphology and muscle strength. This suggests that the neurodegenerative process is slowed or halted at least for a limited period of time since no recovery is possible after 9 months. This time limit is interesting as the time course of $\alpha \mathrm{MN}$ degeneration is very slow with $40 \%$ of the cells still alive at 15.5 months and seems to reach a plateau. It is thus possible that $\alpha \mathrm{MNs}$ are heterogeneous in term of their dependency to EN1. This is reminiscent of the SNpc and Ventral Tegmental Area (VTA) mDA neurons, the two populations expressing Enl, but the latter being more resistant to Enl hypomorphism ${ }^{18}$. It is also interesting to note that forelimb muscle strength was restored suggesting that even the low levels of hEN1 that attain cervical spinal cord have beneficial effects on the remaining $\alpha \mathrm{MNs}$.

Homeoproteins can act cell and non-cell autonomously and this raises two possible mechanisms leading to the phenotype observed in the Enl-Het mice and protection by exogenous hEN1. A direct cell autonomous effect would mean that spinal V1 interneurons are dysfunctional in the Enl-Het mouse. Since these cells are an essential component of the reciprocal inhibitory $\alpha \mathrm{MN}$ circuit, loss of their inhibitory input places $\alpha \mathrm{MNs}$ at risk for degeneration ${ }^{42}$. Deficits in inhibitory interneurons in the spinal cord of motor neuron disease models have been reported ${ }^{43}$ and in particular Renshaw cell pathology has also been observed following $\alpha \mathrm{MN}$ loss ${ }^{44}$. Alternatively, but not mutually exclusive, EN1 might act in a non-cell autonomous fashion. Such non-cell autonomous activities can be of several sorts. Firstly, EN1 may regulate within spinal V1 interneurons the expression of classical trophic factors that support, following their secretion, $\alpha \mathrm{MN}$ survival. Secondly, EN1 might be secreted and internalized by intermediate cell types, such as astrocytes or microglial cells, enhancing their $\alpha \mathrm{MN}$-directed trophic activity ${ }^{45,46}$. Finally, V1 interneurons may provide EN1 to $\alpha \mathrm{MNs}$ where the protein would exert its direct protective activity as observed for OTX2 in RGCs ${ }^{11}$. It is possible that EN1 protects the $\alpha \mathrm{MNs}$ that internalize it through one or several of the EN1-controled mechanisms that protect mDA neurons of the SNpc from oxidative stress ${ }^{20,21}$. 
Among these mechanisms are the regulation, through local protein translation, of Complex I mitochondrial activity ${ }^{19}$, DNA break repair, heterochromatin maintenance and the repression of long interspersed nuclear elements (LINE-1) expression ${ }^{20,24}$. The evaluation of these possibilities will be the object of future studies.

The Enl-Het mouse presents muscle weaknesses, abnormal spinal reflex, NMJ denervation and $\alpha \mathrm{MN}$ loss, all phenotypes highly reminiscent of changes in Amyotrophic Lateral Sclerosis (ALS) patients and in many ALS mouse models. This raises the question as to whether the results reported here are relevant for motor neuron diseases. It is important to note that EnIHet mice do not present a number of important symptoms such as weight loss, respiratory distress, and complete paralysis or endpoint death. The absence of weight loss in the Enl-Het mice may be an effect of the Swiss background mouse line. In contrast to virtually all mouse lines whose body weight asymptotes in mid-adulthood (Jackson Laboratory; https://www.jax.org/\#) both the Enl-Het mice and their WT littermates continue to gain weight reaching about 80 grams at 2 years of age. Thus, it is possible that metabolic defects specific to this genetic background may mask weight losses due to $\alpha \mathrm{MN}$ degeneration.

It is also possible that the extensive $\alpha \mathrm{MN}$ loss up to about $60 \%$ at 15.5 months of age has little or no impact on feeding motor behaviors, although this is difficult to reconcile with the severe phenotypes observed in mouse models of ALS. ALS patients and mice in some ALS models have respiratory or cardiac failure ${ }^{47-49}$. We did not observe any obvious breathing difficulty in the Enl-Het mice and the long-life span of the mice (at least up to two years thus far) indicates no cardiac failure. The phrenic $\alpha \mathrm{MNs}$ that drive respiration are concentrated at the C3-C4 level in mice ${ }^{45}$. Thus, interneuron inhibition on phrenic $\alpha \mathrm{MNs}$ or $\alpha \mathrm{MNs}$ themselves may be insensitive to reduced EN1. At the thoracic level that provides cardiac modulation $47,50,51$, inhibitory Ia interneurons are absent ${ }^{52}$. We did not assess the number or phrenic $\alpha \mathrm{MN}$ in the thoracic spinal cord. It would be interesting to determine if the absence of phrenic and thoracic $\alpha \mathrm{MN}$ loss correlates with the absence of breathing difficulties or cardiac function. With regards to ALS patients, since all $\alpha \mathrm{MNs}$ derive from the same lineage and transcription factor program, it is possible that phrenic and thoracic $\alpha \mathrm{MNs}$ might respond to exogenous hEN1. 


\section{FIGURE LEGENDS}

Figure 1. En1-Het mice show progressive muscle weakness and abnormal spinal reflex RT-qPCR of the lumbar enlargement of 4.5 (a) and 16 (b) month-old Enl-Het mice and WT littermates shows the stable expression of Enl in the WT at both ages and its reduced expression in heterozygous mice. c) There are no differences in body weight between En1Het mice and WT littermates. d) En1-Het mice show reduced normalized grip strength at 3 months of age with increase weakening with age, compared to WT. e) En1-Het mice hold onto the inverted grid less time compared to WT mice starting at two months of age. f) EnlHet mice start to show an abnormal hind limb reflex score at two months of age and this worsens with age. WT littermates show a normal score at all ages. Comparisons by Unpaired T-test with equal SD comparing WT with Enl-Het at each time point $(* \mathrm{p}<0.05 ; * * \mathrm{p}<0.005$; $* * * \mathrm{p}<0.0005 ; * * * * \mathrm{p}<0.0001)$.

\section{Figure 2. En1-Het mice develop NMJ abnormalities}

a) Confocal micrographs of representative images of lumbrical muscle neuromuscular junctions in of the WT and En1-Het mice at 3 months of age stained for 2H3/SV2 (red) and $\alpha$ BTX (green). b) NMJs of Enl-Het and WT mice do not differ in the number of AChR clusters. c) NMJ endplate area is reduced in the Enl-Het mice at 15.5 months of age. d) The maturation state of the endplates as reflected in the percentage of endplates with perforations is similar in the two genotypes through 9 months of age, but a difference appears at 15.5 months, with a reduction in the percentage with perforations in the En1-Het mouse. e) EnlHet mice show a significant decrease in the percentage of fully occupied endplates starting at three months of age and this percentage declines with age compared to WT mice. Scale bar: $100 \mu \mathrm{m}$ applies to all; Comparisons made by Unpaired T-test with equal SD comparing WT with EN1-Het $(* \mathrm{p}<0.05 ; * * \mathrm{p}<0.005 ; * * * \mathrm{p}<0.0005 ; * * * * \mathrm{p}<0.0001)$.

\section{Figure 3. Specific loss of large $\alpha$ MNs in lumbar spinal cord of En1-Het mice}

a) Representative light field micrographs of the left ventral horn of the lumbar enlargement of a WT and an En1-Het mouse at 15.5 months of age, stained with Cresyl violet (arrows point to large cells). b-d) No differences between En1-Het and WT mice were observed for the number of all Cresyl-stained cells, the number of small stained cells nor for the number of medium stained cells. e) A significant reduction in the number of large neurons in the EnIHet mice, first seen at 4.5 months of age increases with time with a nearly $50 \%$ loss in 15.5 - 
month-old En1-Het mice, compared to WT littermates. Scale bar: $100 \mu \mathrm{m}$; Comparisons made by Unpaired T-test with equal SD comparing WT with Enl-Het mice $\left({ }^{*} \mathrm{p}<0.05 ; * * \mathrm{p}<0.005\right.$; $* * * \mathrm{p}<0.0005 ; * * * * \mathrm{p}<0.0001)$.

\section{Figure 4. The large MN are ChAT-positive $\alpha \mathrm{MNs}$}

a) Representative confocal micrographs of the left ventral horn of the lumbar enlargement of the WT and Enl-Het mice at 9 months of age stained for ChAT (Green). b) The number of ChAT+ cell between 200 and $299 \mu \mathrm{m}^{2}$ (putative $\gamma \mathrm{MNs}$ ) is maintained between genotypes. c) Enl-Het mice show a reduction of ChAT + cells with cross-sectional areas $>300 \mu \mathrm{m}^{2}$ (putative $\alpha \mathrm{MNs})$. Scale bar: $100 \mu \mathrm{m}$; Comparisons made by Unpaired T-test with equal SD comparing WT with En1-Het mice $(* \mathrm{p}<0.05 ; * * \mathrm{p}<0.005 ; * * * \mathrm{p}<0.0005 ; * * * * \mathrm{p}<0.0001)$.

Figure 5. Intrathecal hEN1 penetrates the spinal cord parenchyma and reverses the En1-Het motor phenotype

a) Representative confocal micrographs of the lumbar enlargement stained for ChAT (Green) and EN1 (Red) in a WT mouse 24 hours after intrathecal injection of $1 \mu \mathrm{g}$ of hEN1. Arrows show examples of hEN1 internalized by numerous cells. Arrowheads show examples of hEN1 in and/or around vessels. b) Inset of the right ventral horn cervical enlargement showing that hEN1 injected at the lumbar level can reach ChAT-positive cells (arrows) in the cervical region. c) There are no differences in body weight before and after injection. d) Before hEN1 injection, Enl-Het mice have reduced forepaw grip strength and hEN1 injection at 3 months of age restores normal strength in 4.5-month-old En1-Het mice. e) Before hEN1 treatment, En1-Het mice hold onto the inverted grid less time that WT littermates and hEN1 injection at 3 months of age restores normal strength in 4.5-month-old En1-Het mice. f) En1-Het mice show an abnormal hind limb extensor score compared to WT and hEN1 injection at 3 months of age restores normal scores in 4.5-month-old Enl-Het mice. Scale bar: $500 \mu \mathrm{m}$. Comparisons made by Unpaired T-test with equal SD $\left({ }^{*} \mathrm{p}<0.05 ; * * \mathrm{p}<0.005 ; * * * \mathrm{p}<0.0005\right.$; $* * * * \mathrm{p}<0.0001)$.

\section{Figure 6. Intrathecal hEN1 preserves NMJ innervation and promotes $\alpha \mathrm{MN}$ survival}

a) En1-Het mice treated with vehicle show a significant reduction in the number of endplates that are fully innervated; those treated with hEN1 have a percentage of fully occupied endplates similar to that found for in WT mice. b) Vehicle-treated Enl-Het mice show a 
significant loss of large neurons stained with Cresyl violet while those treated with hEN1 show a complete protection against loss. c) Vehicle-treated Enl-Het mice show a significant loss of large ChAT $+\alpha M N s$, while En1-Het mice treated with hEN1 show complete protection. Comparisons made by Unpaired T-test with equal SD $(* \mathrm{p}<0.05$; $* * \mathrm{p}<0.005$; $* * * \mathrm{p}<0.0005 ; * * * * \mathrm{p}<0.0001)$

Figure 7. A single dose of hEN1 injected at 3 months of age, but not at 9 months, has a long-lasting effect on En1-Het mice behavior

a) Before hEN1 injection Enl-Het mice have reduced weight normalized grip strength but within one week after hEN1 injection the mice have normal or near normal forepaw grip strength. This improvement lasts up to three months. Note that the forepaw grip strength in nine-month-old hEN1-treated En1-Het mice is slightly better than in age-matched non-treated En1-Het mice (open square). b) Before hEN1 injection En1-Het mice held onto the inverted grid for shorter times that WT mice. After hEN1 the time holding onto the grid improved somewhat up to three months after injection and then declined. The time holding onto the grid by 9-month-old hEN1-treated En1-Het mice is significantly improved compared to agematched non-treated Enl-Het mice (open square) c) Three-month-old Enl-Het mice have an abnormal hind limb extensor reflex compared to WT mice. Within one week after hEN1 the extensor score is normalized to the WT score, remains normal up to two months and then declines. At the end of the experiment the extensor score of 9-month-old hEN1-treated EnIHet mice is significantly better than in age-matched non-treated Enl-Het mice (open square). d-f) Nine-month-old Enl-Het mice performed worse than WT mice in the three tests. Intrathecal hEN1 injection at 9 months of age did not improve performance over the next six and a half months compared to non-treated littermates.

Figure 8. A single dose of hEN1 injected at 3 months of age, but not at 9 months, has a partial protective effect on NMJ morphology and $\alpha \mathrm{MN}$ survival

a) In 9-month-old En1-Het mice treated with hEN1 the percentage of fully occupied endplates was significantly reduced compared to WT mice, but significantly greater that in 9-month-old non-treated En1-Het mice. b) In 9-month-old hEN1-treated En1-Het mice the number of $\alpha \mathrm{MNs}$ in the lumbar spinal cord was less than in WT mice but significantly higher than on age-matched non-treated En1-Het mice. c,d) Fifteen and a half month old Enl-Het mice treated with hEN1 at 9 months of age showed no improvement in fully occupied endplates or 
$\alpha \mathrm{MN}$ survival compared to untreated Enl-Het mice. $(* \mathrm{p}<0.05 ; * * \mathrm{p}<0.005 ; * * * \mathrm{p}<0.0005$ $* * * * \mathrm{p}<0.0001)$.

\section{References}

1. Gehring, W. J. Homeo boxes in the study of development. Science 236, 1245-1252 (1987).

2. Spatazza, J. et al. Homeoprotein signaling in development, health, and disease: a shaking of dogmas offers challenges and promises from bench to bed.

Pharmacological Reviews 65, 90-104 (2013).

3. Prochiantz, A. \& Di Nardo, A. A. Homeoprotein signaling in the developing and adult nervous system. Neuron 85, 911-925 (2015).

4. Bobola, N. \& Merabet, S. Homeodomain proteins in action: similar DNA binding preferences, highly variable connectivity. Current Opinion in Genetics \& Development 43, 1-8 (2017).

5. Di Nardo, A. A., Fuchs, J., Joshi, R. L., Moya, K. L. \& Prochiantz, A. The Physiology of Homeoprotein Transduction. Physiological Reviews 98, 1943-1982 (2018).

6. Derossi, D., Chassaing, G. \& Prochiantz, A. Trojan peptides: the penetratin system for intracellular delivery. Trends in Cell Biology 8, 84-87 (1998).

7. Maizel, A., Bensaude, O., Prochiantz, A. \& Joliot, A. A short region of its homeodomain is necessary for engrailed nuclear export and secretion. Development 126, 3183-3190 (1999).

8. Joliot, A. \& Prochiantz, A. Transduction peptides: from technology to physiology. Nat Cell Biol 6, 189-196 (2004).

9. Lee, E. J. et al. Global Analysis of Intercellular Homeodomain Protein Transfer. CellReports 28, 712-722.e3 (2019).

10. Sugiyama, S. et al. Experience-dependent transfer of Otx2 homeoprotein into the visual cortex activates postnatal plasticity. Cell 134, 508-520 (2008).

11. Torero Ibad, R. et al. Otx2 promotes the survival of damaged adult retinal ganglion cells and protects against excitotoxic loss of visual acuity in vivo. J. Neurosci. 31, 5495-5503 (2011).

12. Bernard, C. et al. Graded Otx2 activities demonstrate dose-sensitive eye and retina phenotypes. Hum. Mol. Genet. 23, 1742-1753 (2014).

13. Di Lullo, E. et al. Paracrine Pax6 activity regulates oligodendrocyte precursor cell migration in the chick embryonic neural tube. Development 138, 4991-5001 (2011).

14. Kaddour, H. et al. Extracellular Pax6 Regulates Tangential Cajal-Retzius Cell Migration in the Developing Mouse Neocortex. Cereb. Cortex (2019). doi:10.1093/cercor/bhz098

15. Brunet, I. et al. The transcription factor Engrailed-2 guides retinal axons. Nature 438, 94-98 (2005).

16. Wizenmann, A. et al. Extracellular Engrailed participates in the topographic guidance of retinal axons in vivo. Neuron 64, 355-366 (2009).

17. Kim, N. et al. Regulation of retinal axon growth by secreted Vax1 homeodomain protein. eLife 3, e02671 (2014).

18. Sonnier, L. et al. Progressive loss of dopaminergic neurons in the ventral midbrain of adult mice heterozygote for Engrailed1. J. Neurosci. 27, 1063-1071 (2007).

19. Alvarez-Fischer, D. et al. Engrailed protects mouse midbrain dopaminergic neurons 
against mitochondrial complex I insults. Nat Neurosci 14, 1260-1266 (2011).

20. Rekaik, H. et al. Engrailed Homeoprotein Protects Mesencephalic Dopaminergic Neurons from Oxidative Stress. CellReports 13, 242-250 (2015).

21. Thomasson, N. et al. Engrailed-1 induces long-lasting behavior benefit in an experimental Parkinson primate model. Mov Disord. 34, 1082-1084 (2019).

22. Brunet, I., Di Nardo, A. A., Sonnier, L., Beurdeley, M. \& Prochiantz, A. The topological role of homeoproteins in the developing central nervous system. Trends in Neurosciences 30, 260-267 (2007).

23. Stettler, O. et al. Engrailed homeoprotein recruits the adenosine A1 receptor to potentiate ephrin A5 function in retinal growth cones. Development 139, 215-224 (2012).

24. Blaudin de Thé, F.-X. et al. Engrailed homeoprotein blocks degeneration in adult dopaminergic neurons through LINE-1 repression. The EMBO Journal 37, (2018).

25. Saueressig, H., Burrill, J. \& Goulding, M. Engrailed-1 and netrin-1 regulate axon pathfinding by association interneurons that project to motor neurons. Development 126, 4201-4212 (1999).

26. Wenner, P., O'Donovan, M. J. \& Matise, M. P. Topographical and physiological characterization of interneurons that express engrailed-1 in the embryonic chick spinal cord. J. Neurophysiol. 84, 2651-2657 (2000).

27. Higashijima, S. I. Engrailed-1 Expression Marks a Primitive Class of Inhibitory Spinal Interneuron. Journal of Neuroscience 24, 5827-5839 (2004).

28. Sapir, T. Pax6 and Engrailed 1 Regulate Two Distinct Aspects of Renshaw Cell Development. Journal of Neuroscience 24, 1255-1264 (2004).

29. Bikoff, J. B. et al. Spinal Inhibitory Interneuron Diversity Delineates Variant Motor Microcircuits. Cell 165, 207-219 (2016).

30. Ramírez-Jarquín, U. N., Lazo-Gómez, R., Tovar-y-Romo, L. B. \& Tapia, R. Spinal inhibitory circuits and their role in motor neuron degeneration. Neuropharmacology 82 , 101-107 (2014).

31. Zhang, Y. et al. V3 spinal neurons establish a robust and balanced locomotor rhythm during walking. Neuron 60, 84-96 (2008).

32. Benito-Gonzalez, A. \& Alvarez, F. J. Renshaw cells and Ia inhibitory interneurons are generated at different times from $\mathrm{p} 1$ progenitors and differentiate shortly after exiting the cell cycle. J. Neurosci. 32, 1156-1170 (2012).

33. Hanks, M., Wurst, W., Anson-Cartwright, L., Auerbach, A. B. \& Joyner, A. L. Rescue of the En-1 mutant phenotype by replacement of En-1 with En-2. Science 269, 679682 (1995).

34. Sleigh, J. N., Burgess, R. W., Gillingwater, T. H. \& Cader, M. Z. Morphological analysis of neuromuscular junction development and degeneration in rodent lumbrical muscles. Journal of Neuroscience Methods 227, 159-165 (2014).

35. Aida, Y. \& Pabst, M. J. Removal of endotoxin from protein solutions by phase separation using Triton X-114. J. Immunol. Methods 132, 191-195 (1990).

36. Comley, L. H., Nijssen, J., Frost-Nylen, J. \& Hedlund, E. Cross-disease comparison of amyotrophic lateral sclerosis and spinal muscular atrophy reveals conservation of selective vulnerability but differential neuromuscular junction pathology. J. Comp. Neurol. 524, 1424-1442 (2016).

37. Sanes, J. R. \& Lichtman, J. W. Development of the vertebrate neuromuscular junction. Annu. Rev. Neurosci. 22, 389-442 (1999).

38. Powis, R. A. \& Gillingwater, T. H. Selective loss of alpha motor neurons with sparing of gamma motor neurons and spinal cord cholinergic neurons in a mouse model of spinal muscular atrophy. J Anatomy 228, 443-451 (2016). 
39. Le Roux, I., Joliot, A. H., Bloch-Gallego, E., Prochiantz, A. \& Volovitch, M.

Neurotrophic activity of the Antennapedia homeodomain depends on its specific DNAbinding properties. Proc Natl Acad Sci USA 90, 9120-9124 (1993).

40. Beurdeley, M. et al. Otx2 Binding to Perineuronal Nets Persistently Regulates Plasticity in the Mature Visual Cortex. Journal of Neuroscience 32, 9429-9437 (2012).

41. Nordström, U. et al. Progressive nigrostriatal terminal dysfunction and degeneration in the engrailed 1 heterozygous mouse model of Parkinson's disease. Neurobiology of Disease 73, 70-82 (2015).

42. Quinlan, K. A. Links between electrophysiological and molecular pathology of amyotrophic lateral sclerosis. Integr. Comp. Biol. 51, 913-925 (2011).

43. Hossaini, M. et al. Spinal Inhibitory Interneuron Pathology Follows Motor Neuron Degeneration Independent of Glial Mutant Superoxide Dismutase 1 Expression in SOD1-ALS Mice. Journal of Neuropathology and Experimental Neurology 70, 662677 (2011).

44. Chang, Q. \& Martin, L. J. Glycinergic innervation of motoneurons is deficient in amyotrophic lateral sclerosis mice: a quantitative confocal analysis. The American Journal of Pathology 174, 574-585 (2009).

45. Qian, K. et al. Sporadic ALS Astrocytes Induce Neuronal Degeneration In Vivo. Stem Cell Reports 8, 843-855 (2017).

46. Barber, S. C., Mead, R. J. \& Shaw, P. J. Oxidative stress in ALS: a mechanism of neurodegeneration and a therapeutic target. Biochim. Biophys. Acta 1762, 1051-1067 (2006).

47. Simonds, A. K. Recent advances in respiratory care for neuromuscular disease. Chest 130, 1879-1886 (2006).

48. Asai, H. et al. Sympathetic disturbances increase risk of sudden cardiac arrest in sporadic ALS. Journal of the Neurological Sciences 254, 78-83 (2007).

49. Corcia, P. et al. Causes of death in a post-mortem series of ALS patients. Amyotroph Lateral Scler 9, 59-62 (2008).

50. Tsuchida, T. et al. Topographic organization of embryonic motor neurons defined by expression of LIM homeobox genes. Cell 79, 957-970 (1994).

51. Tosney, K. W., Hotary, K. B. \& Lance-Jones, C. Specifying the target identity of motoneurons. Bioessays 17, 379-382 (1995).

52. Wang, Z., Li, L., Goulding, M. \& Frank, E. Early postnatal development of reciprocal Ia inhibition in the murine spinal cord. J. Neurophysiol. 100, 185-196 (2008). 
a

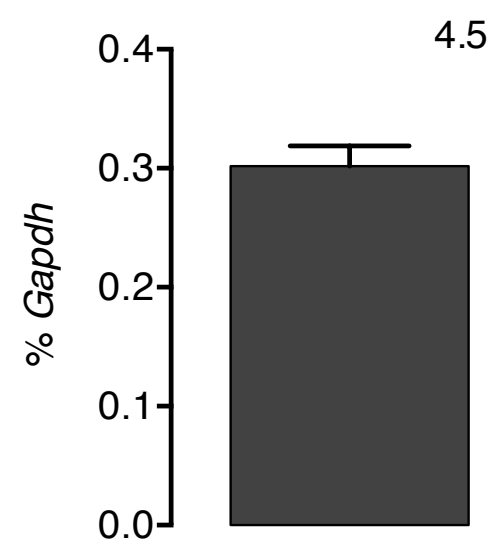

WT

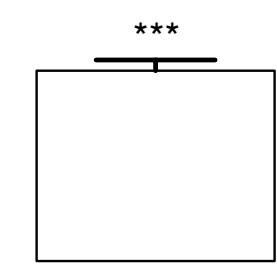

En1-Het

\section{C}

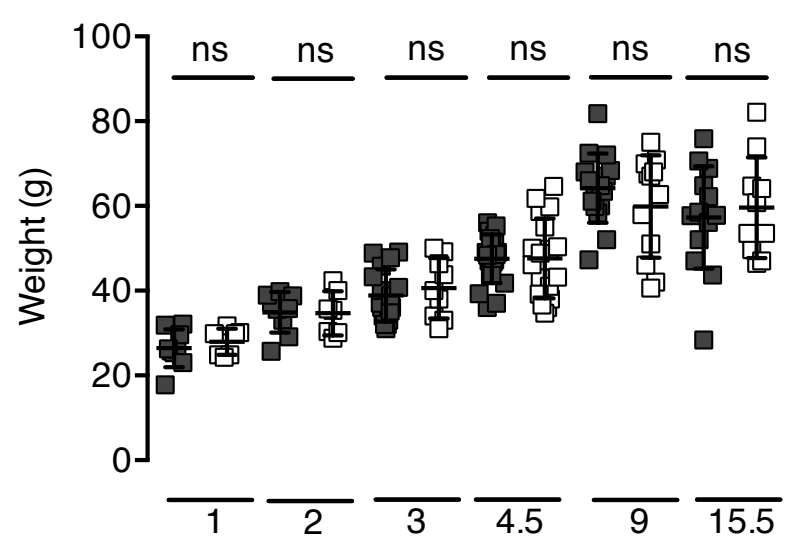

e

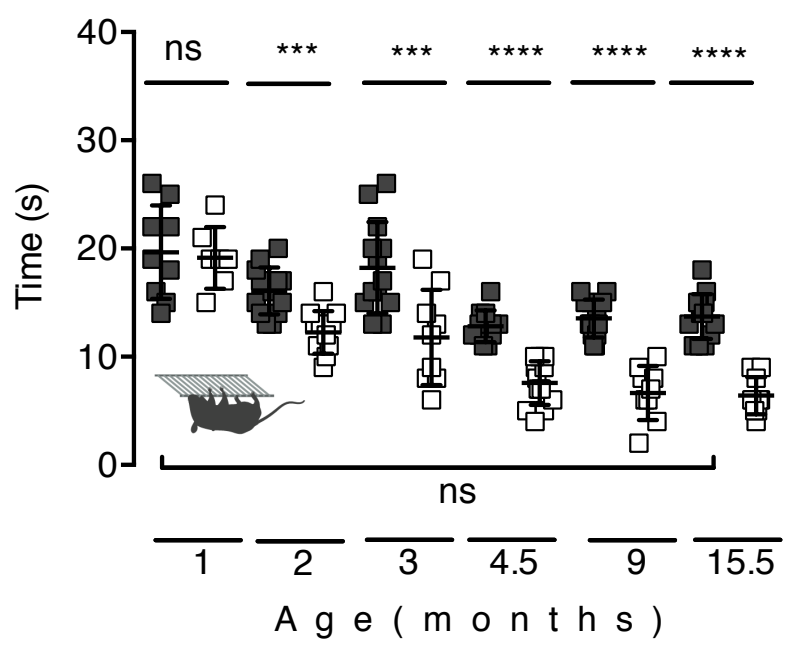

b

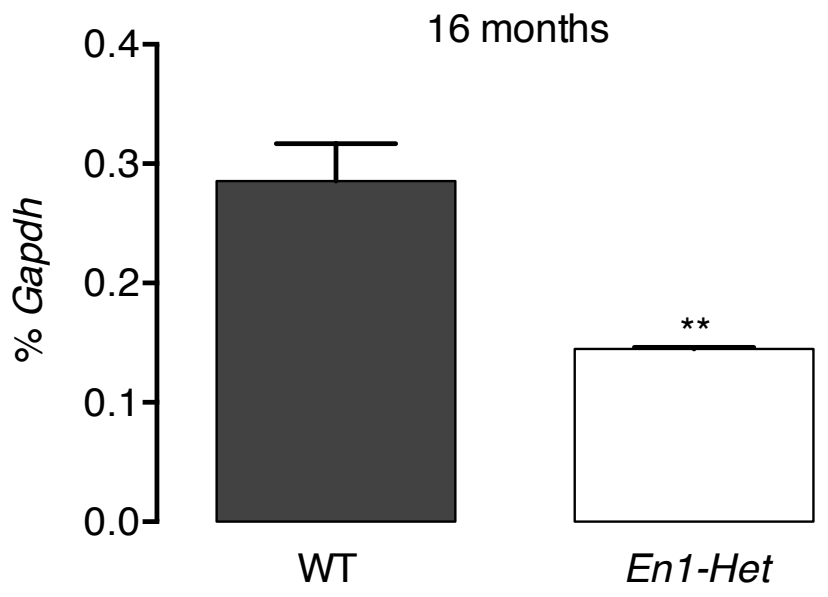

d
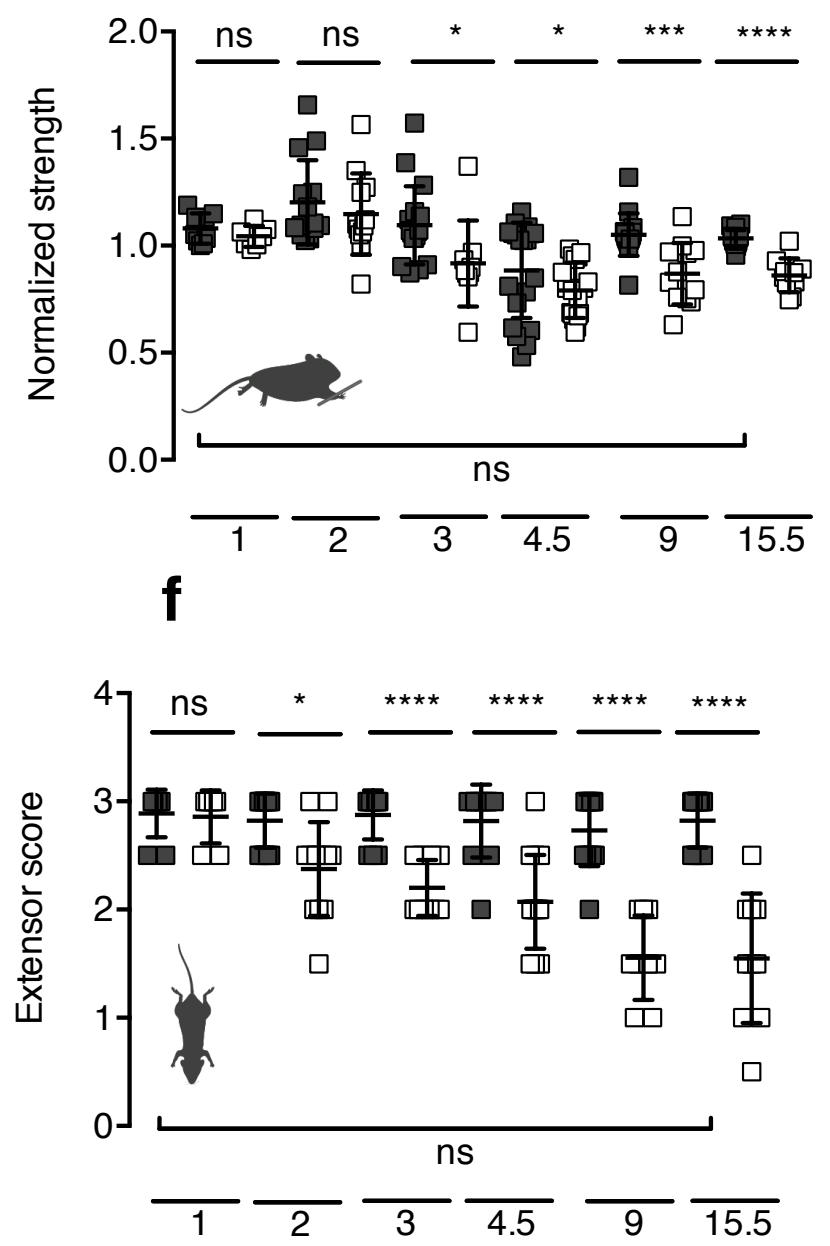

A ge ( months)

$\square$ WT $\square$ En1-Het

Figure 1 
a
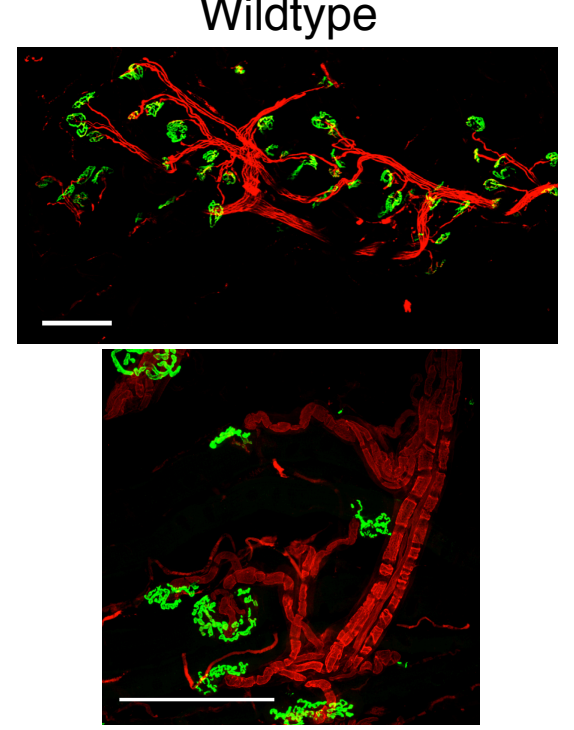

b

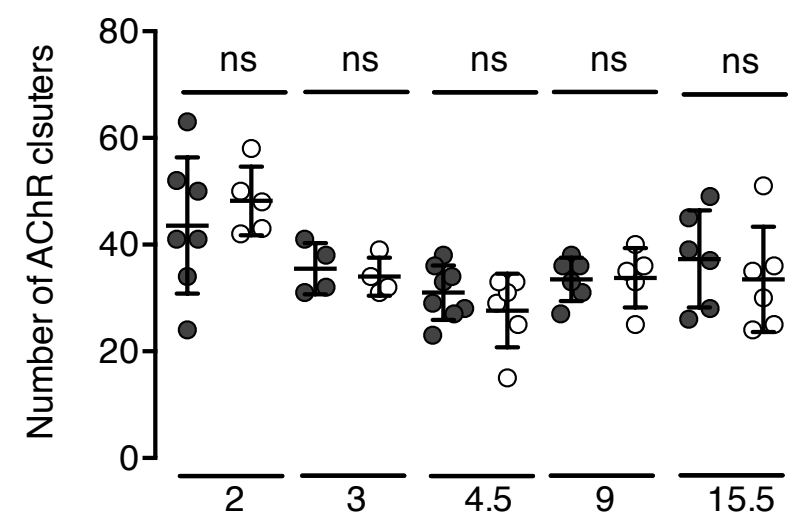

d

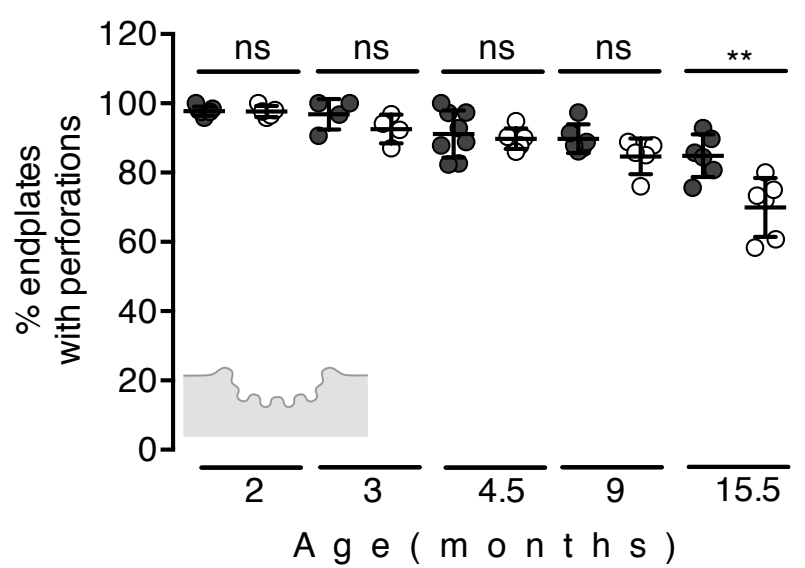

En1-Het
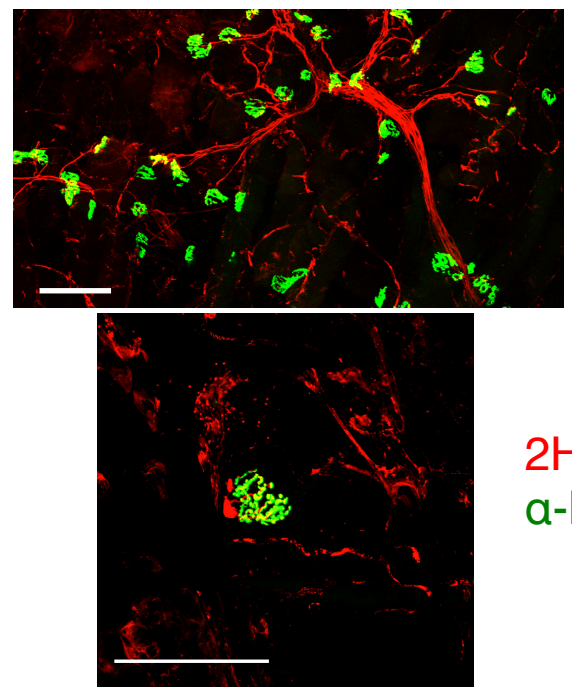

2H3/SV2 a-BTX

\section{C}
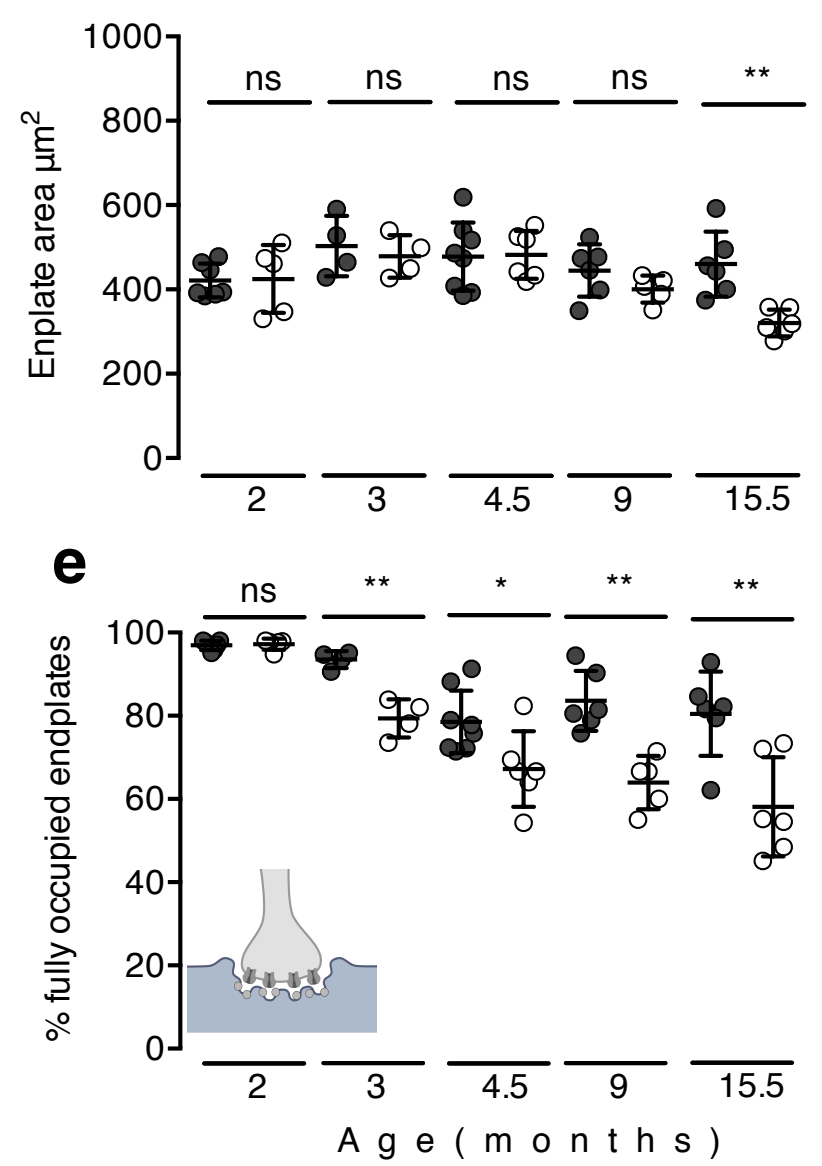

WT OEn1-Het

\section{Figure 2}


bioRxiv preprint first posted online Aug. 13, 2019; doi: http://dx.doi.org/10.1101/734020. The copyright holder for this preprint (which was not peer-reviewed) is the author/funder, who has granted bioRxiv a license to display the preprint in perpetuity. All rights reserved. No reuse allowed without permission.

a

Wildtype

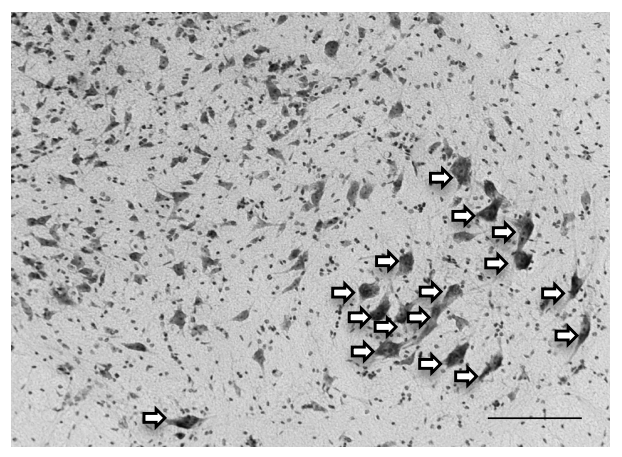

b
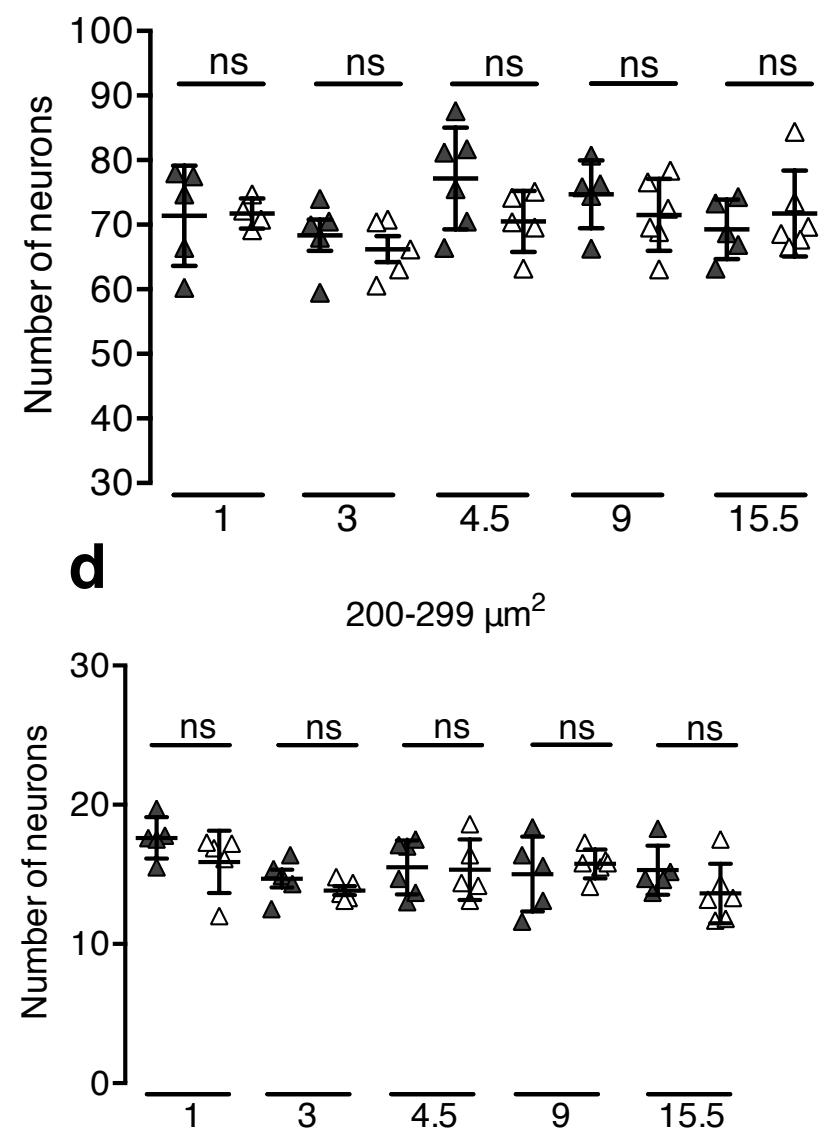

A g e ( $m$ o $n t h s)$
En1-Het
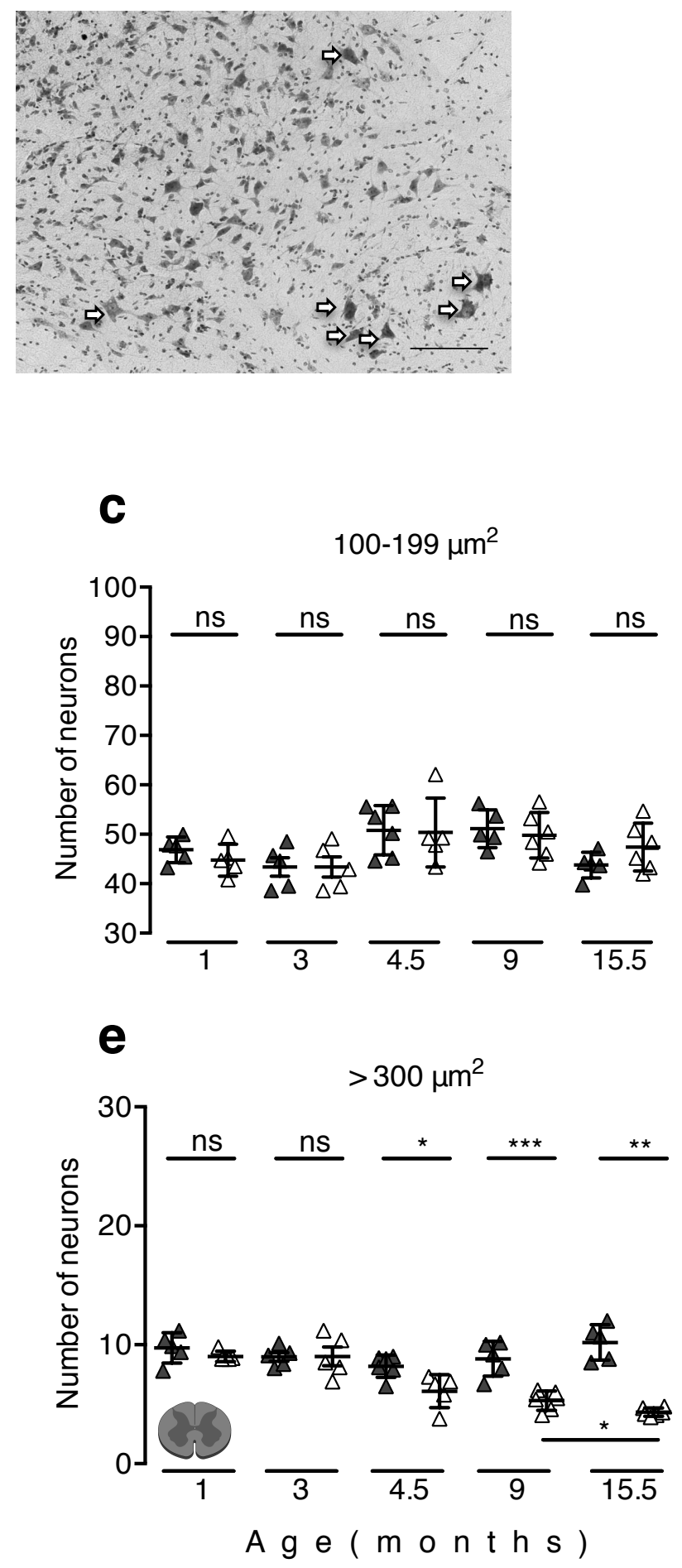

Figure 3 

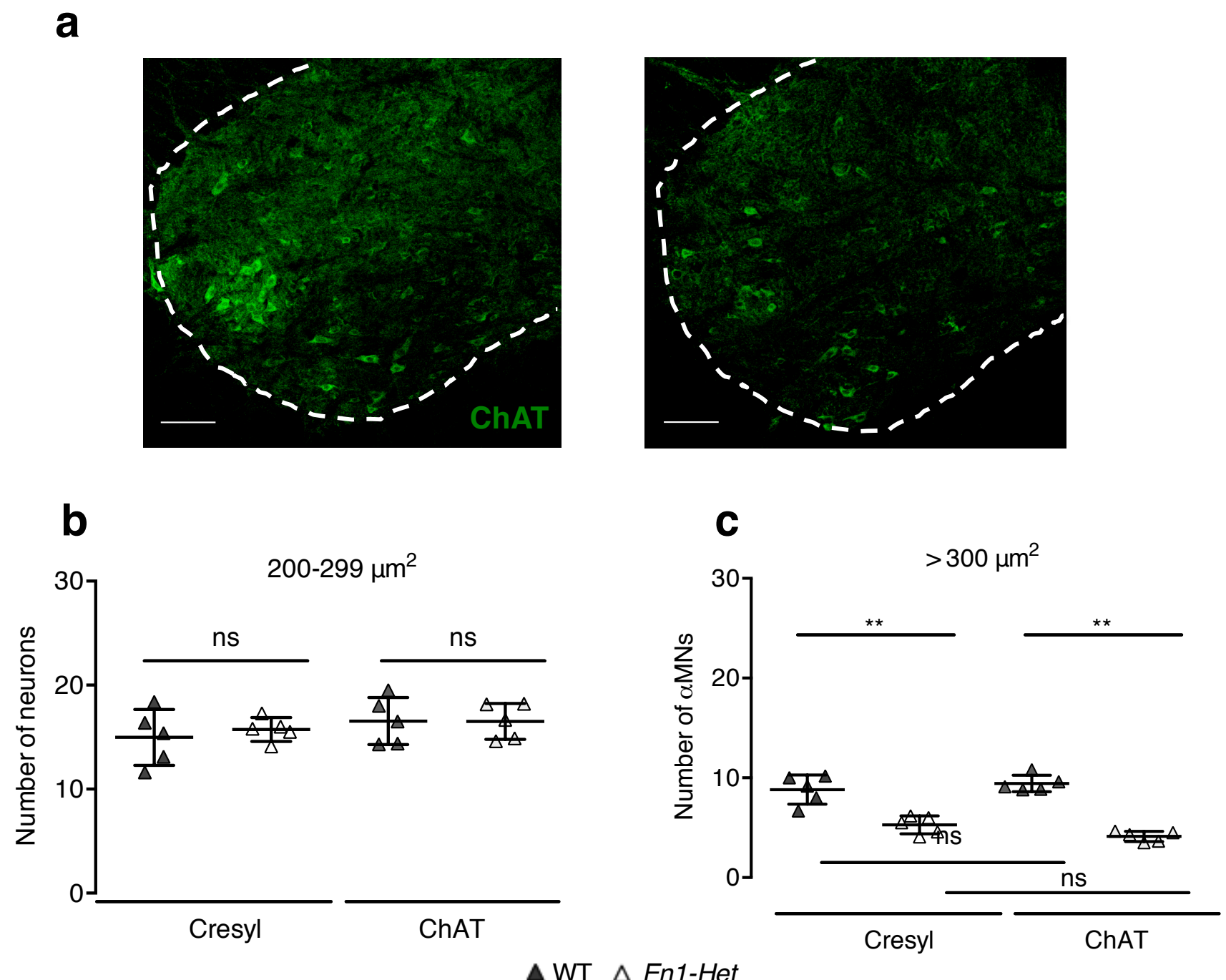

Figure 4 
a

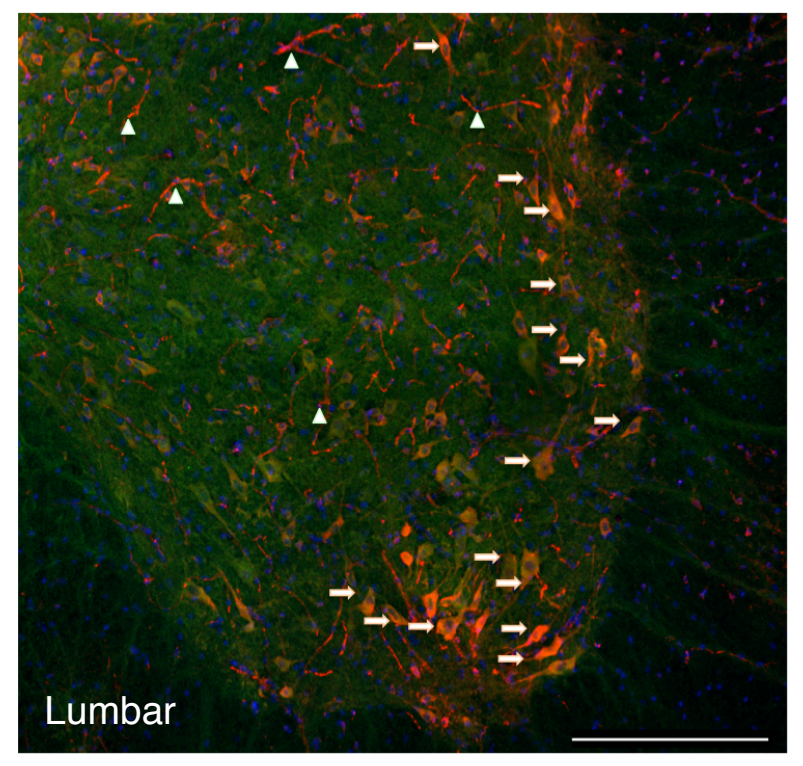

C

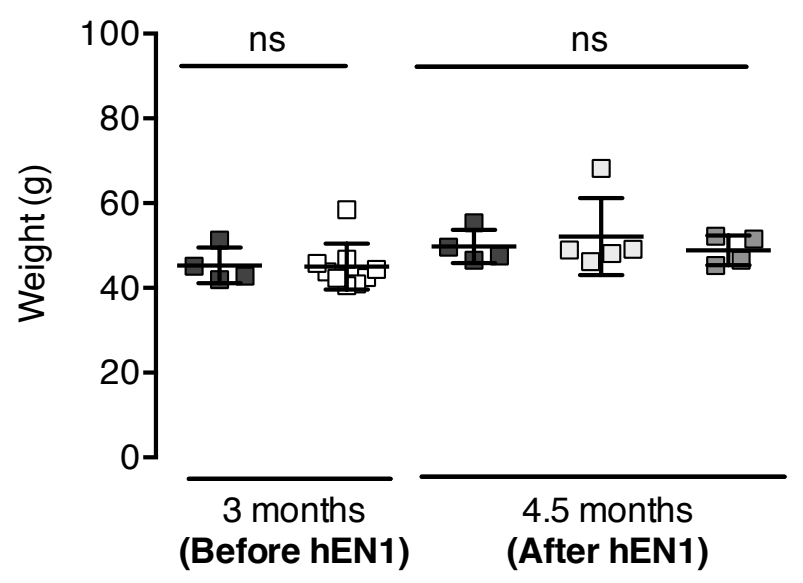

e

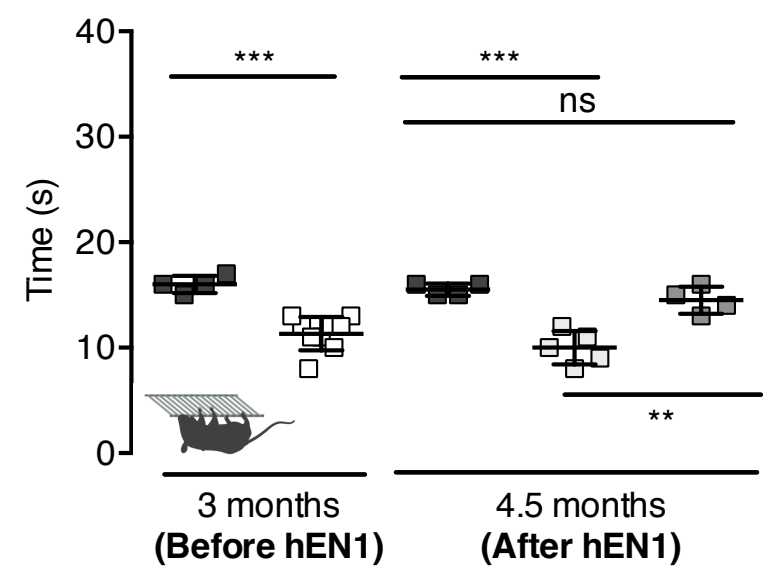

b
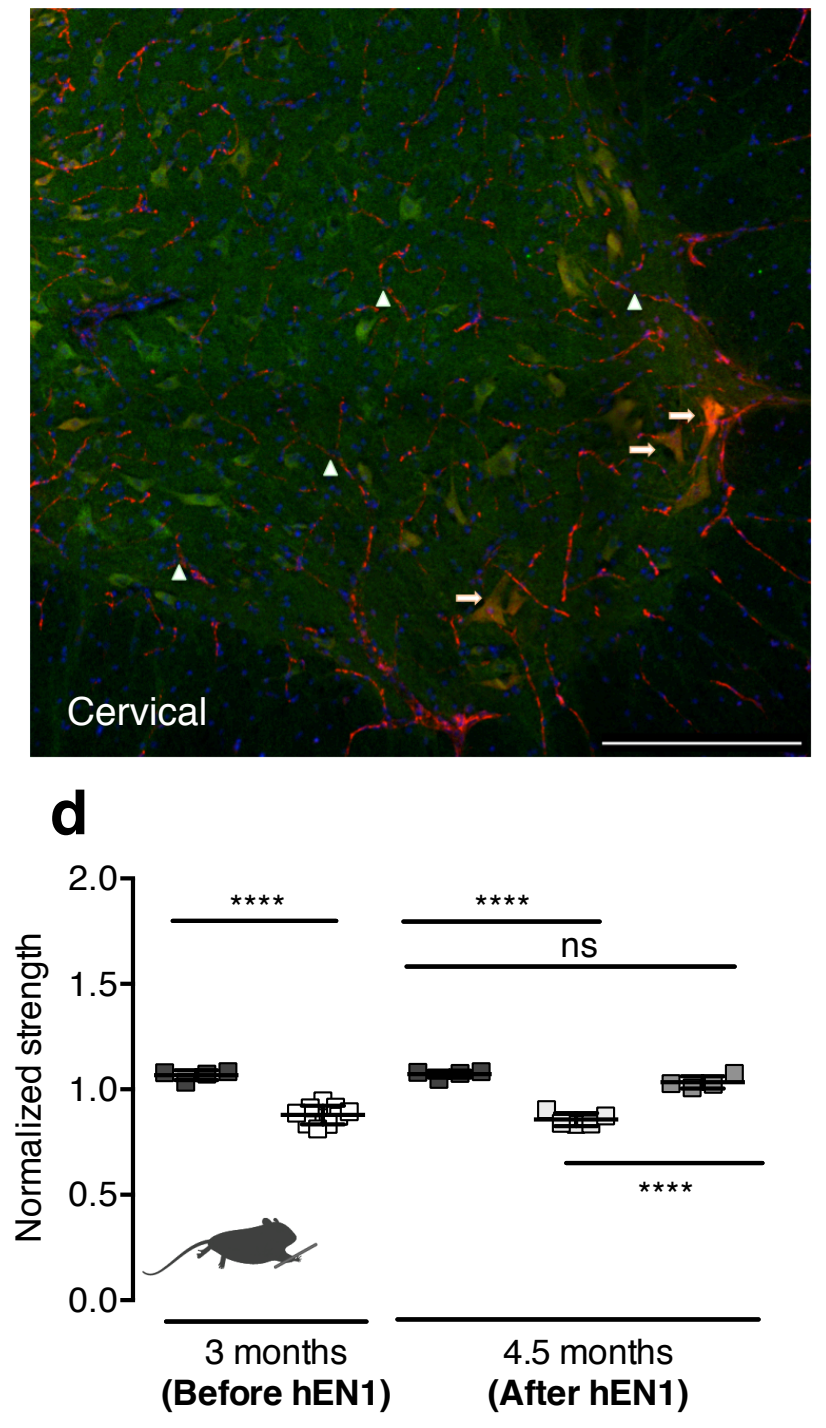

f

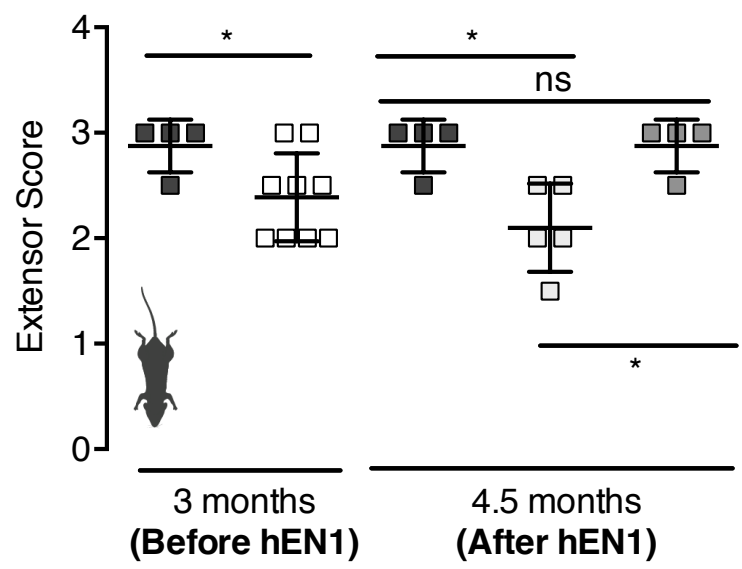

$\square \mathrm{WT} \square$ En1-Het
$\square$ En1-Het $\square$ En1-Het
+ Veh +hEN1

Figure 5 

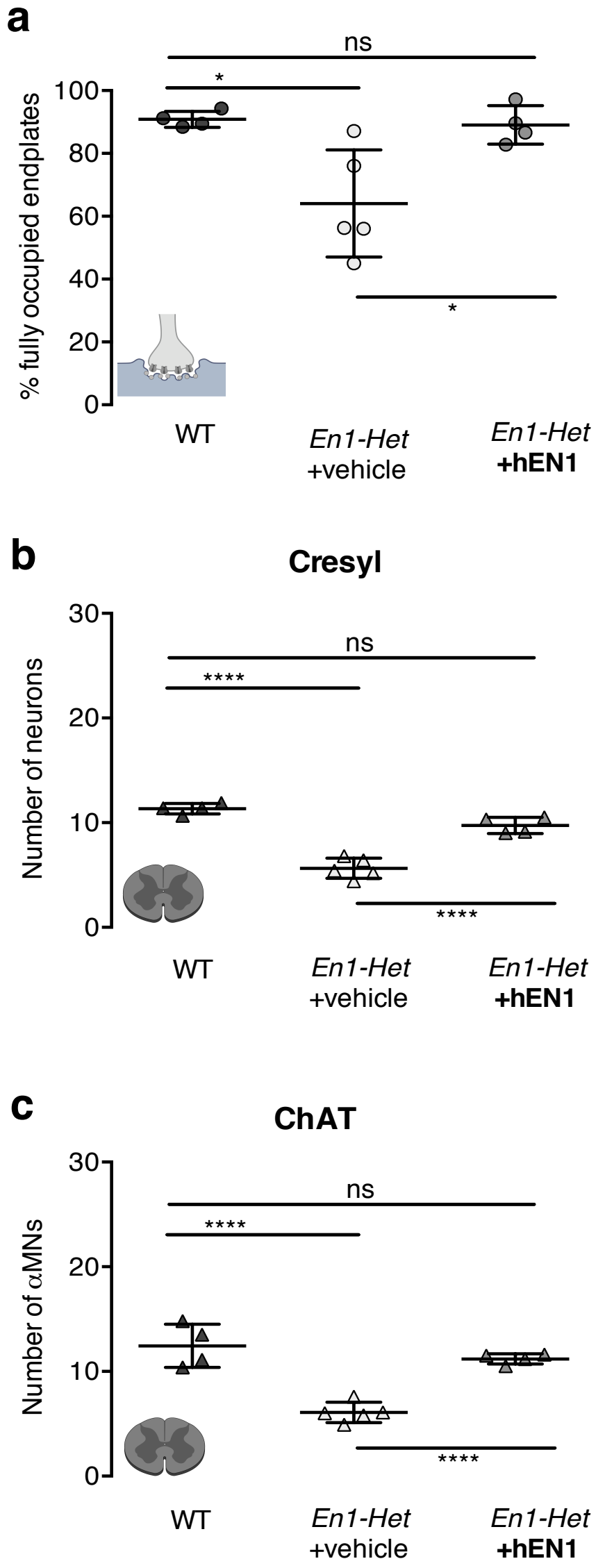

Figure 6 

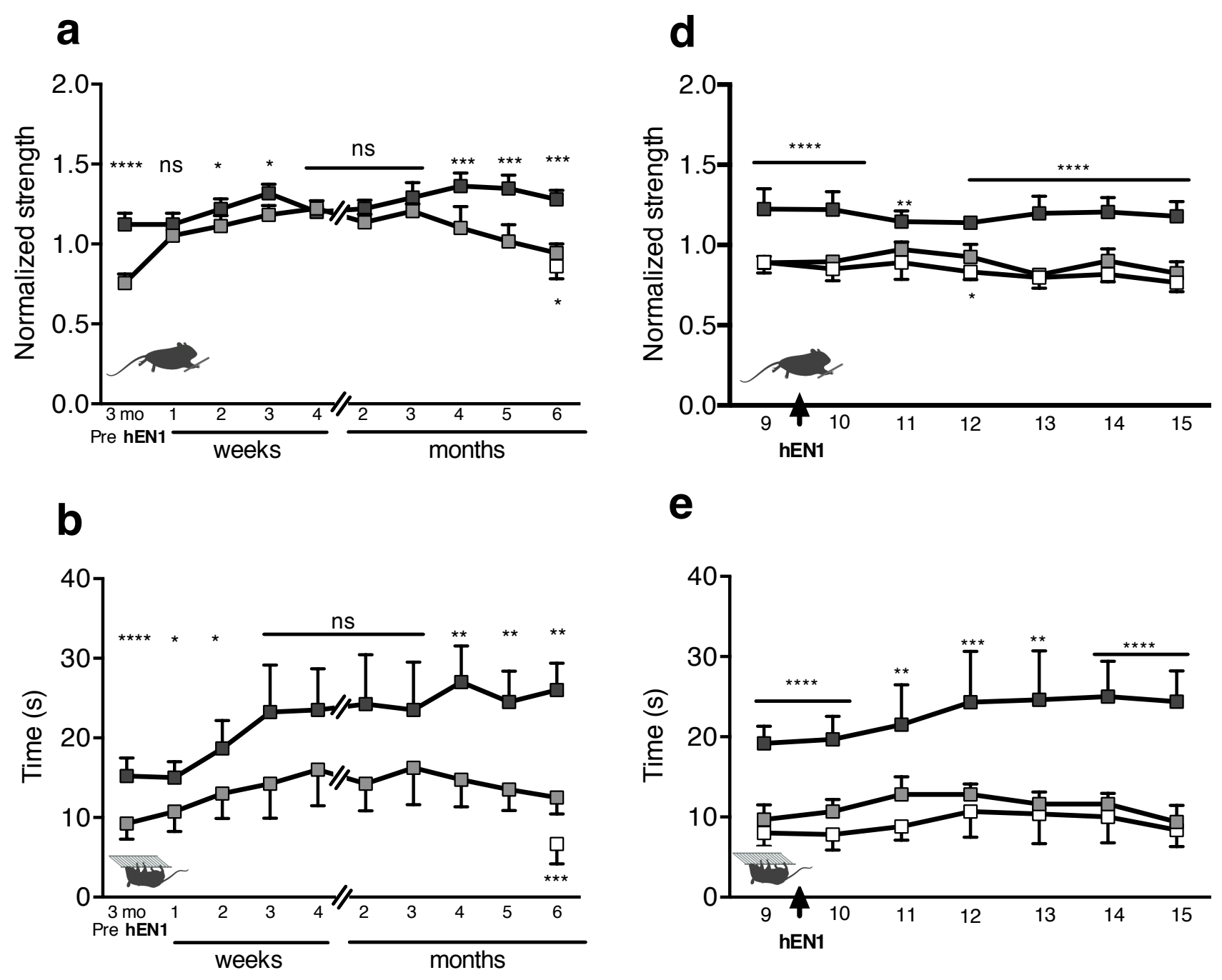

e
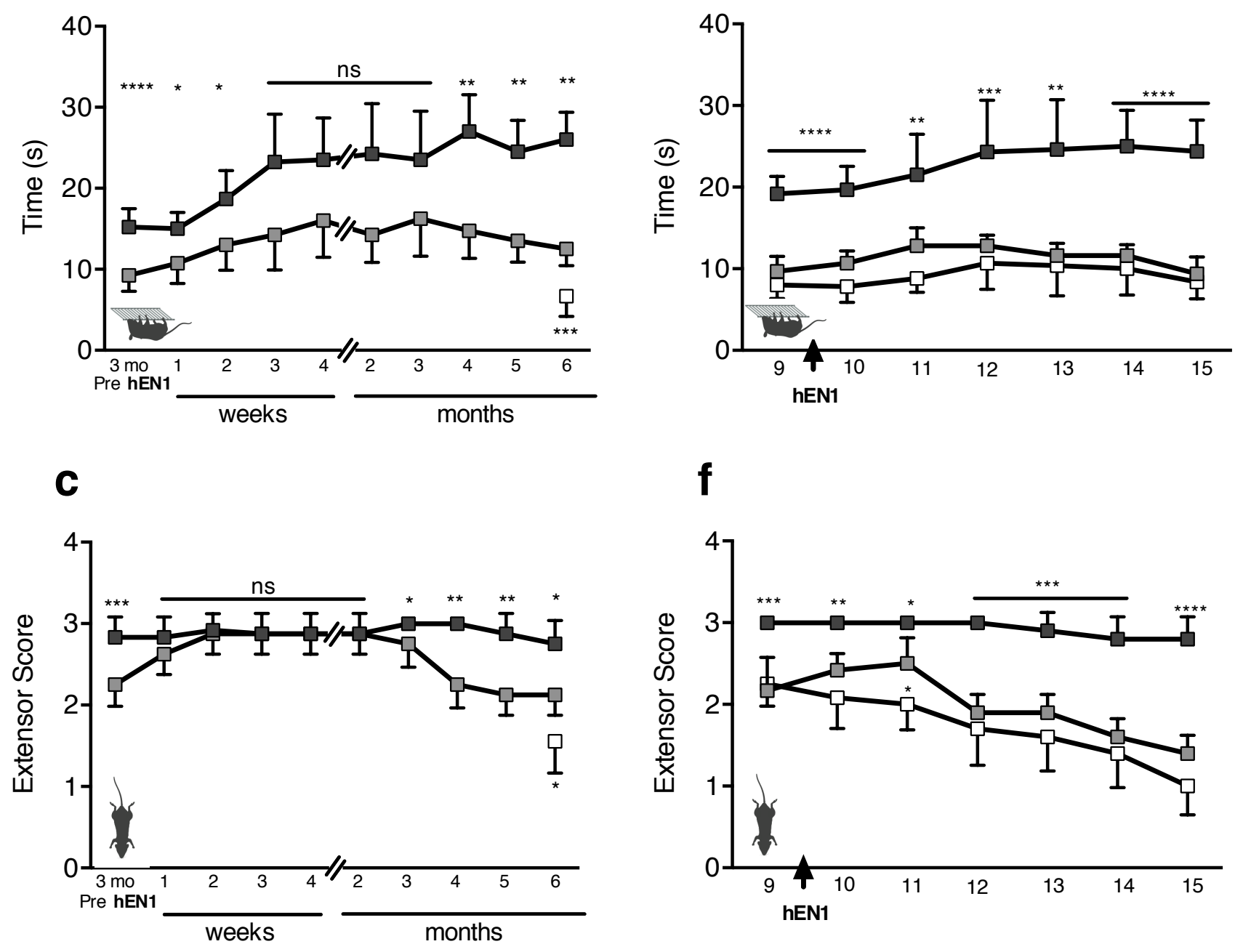

$\square \mathrm{WT} \quad \square$ En1-Het $\begin{array}{r}\text { En1-Het } \\ + \text { hEN1 }\end{array}$

Figure 7 

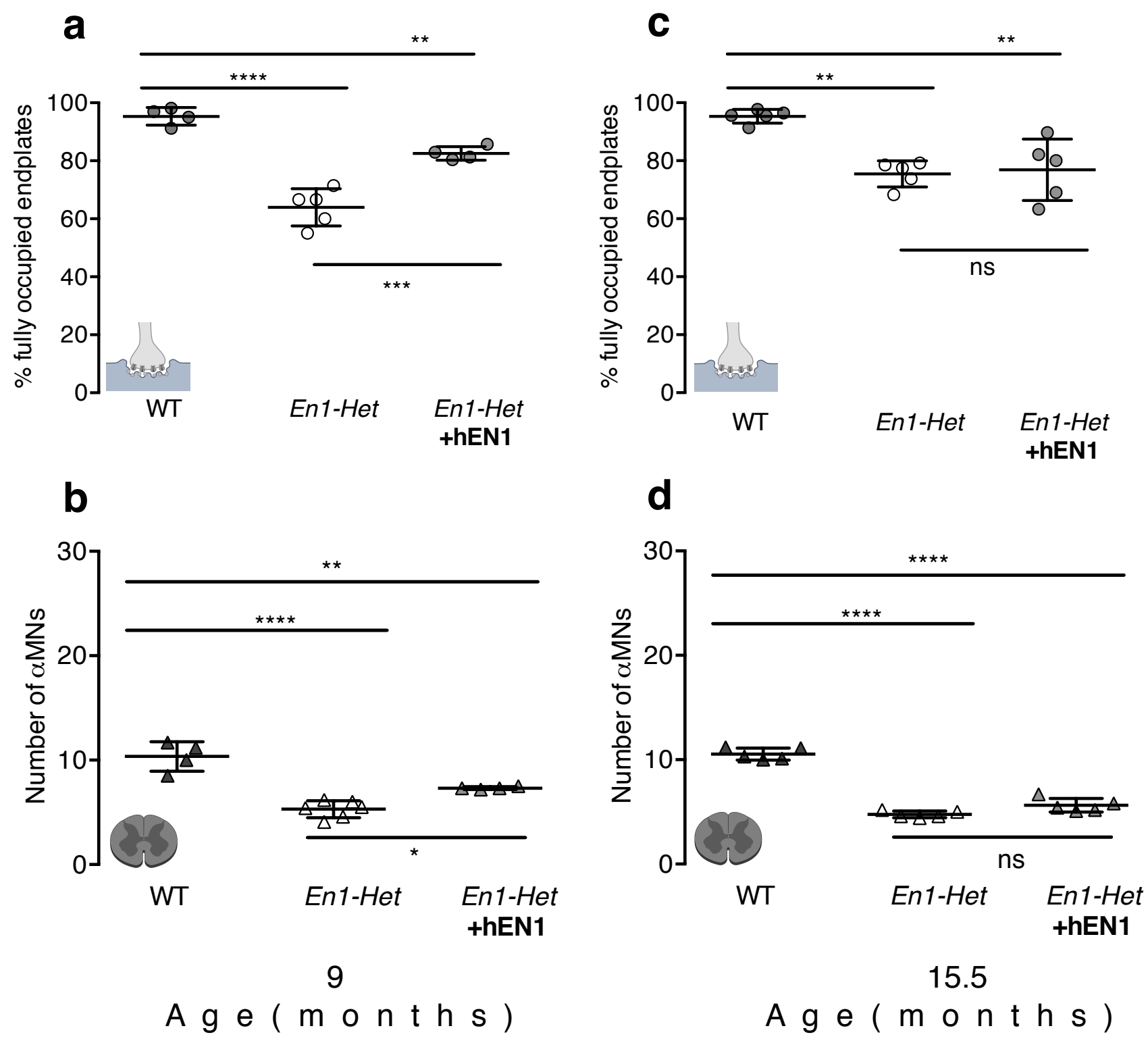

Figure 8 